\title{
Untersuchungen über die Trübungsverhältnisse, die Durchsichtigkeit und die Wasserfarbe in schweizerischen Gewässern
}

\author{
Von O. JAAG und E. MÄrKI
}

Eidg. Anstalt für Wasserversorgung, Abwasserreinigung und Gewässerschutz an der Eidg. Technischen Hochschule in Zürich

Manuskript eingegangen am ıo. Dezember 1962

\section{INHALT}

Vormort. . . . . . . . . . . . . . . . . . . . . . . . . . . . . 2

A. Allgemeines und theoretiscbe Grundlagen . . . . . . . . . . . . . . . . . 2

I. Ursachen und Wirkung der Wassertrübung . . . . . . . . . . . . 3

2. Die Wasserfarbe unserer Seen. . . . . . . . . . . . . . . 6

B. Methodik . . . . . . . . . . . . . . . . . . . . . . . . . . . . . 8

1. Trübungsmessung . . . . . . . . . . . . . . . . . . . . . . 8

2. Transparenzmessung . . . . . . . . . . . . . . . . . . . . . . 9

3. Beurteilung der Eigenfarbe eines Sees . . . . . . . . . . . . . . 9

4. Gruppierung der untersuchten Gewässer nach ihrem mittleren Trübungswert ...................... . I0

C. Zusammenbang zwischen Trübung, Transparenz und Seefarbe . . . . . . . . . II

D. Die natürlicbe Klärung des Wassers in perscbiedenen Gemässersystemen . . . . I9

I. Die Aare vom Oberaargletscher bis zum Bielersee . . . . . . . . . . I9

2. System Reuss-Vierwaldstättersee . . . . . . . . . . . . . . . . 2 I

3. System Broye-Murtensee-Lac de Neuchâtel-Bielersee . . . . . . . . 22

4. System Lungernsee-Sarnersee--Vierwaldstättersee . . . . . . . . . 24

5. System Ägerisee-Zugersee-Lorze . . . . . . . . . . . . . . . . 25

6. System des Inn und der Oberengadiner Seen . . . . . . . . . . . . 26

7. Der Ova del Bernina und sein Einzugsgebiet . . . . . . . . . . . . 28

8. Ritomsee und Lago di Cadagno. . . . . . . . . . . . . . . . . . 29

9. Das Gewässersystem des Rheins . . . . . . . . . . . . . . . . . 3 I

E. Die Klärung (Sedimentation) der Mineralstoffe getrübter $W$ ässer aus perscbiedenen Flußsystemen (Laborversucbe) . . . . . . . . . . . . . . . . . . . . 35

Zusammenfassung . . . . . . . . . . . . . . . . . . . . . 49

Literaturperzeichnis . . . . . . . . . . . . . . . . . . . . . $5 \mathbf{I}$ 


\section{Vorwort}

Die vorliegende Studie bildet einen in sich geschlossenen Teil umfangreicher Untersuchungen, welche die Verfasser in den vierziger und fünfziger Jahren im Auftrag des Eidg. Amtes für Wasserwirtschaft durchführten. Zunächst handelte es sich damals darum, einen Grund zu finden für die vom Auftraggeber in neuerer Zeit festgestellten Veränderungen in den Gefällsverhältnissen zwischen Bodensee und Untersee. Über die Ergebnisse jener Untersuchungen wurde ein Bericht verfasst, der am 3I. Januar I953 dem Eidg. Amt für Wasserwirtschaft vorgelegt wurde.

In der Folge erhielten die Verfasser vom gleichen Amt den Auftrag, eine Reihe weiterer Fragen abzuklären, welche mit der immer weiteren Ausbreitung der Burgunderblutalge Oscillatoria rubescens in schweizerischen und ausländischen Seen zusammenhingen.

In diesen umfangreichen Arbeiten stand $u$. a. auch die Frage der Trübungsverhältnisse schweizerischer Gewässersysteme, sodann die des $\mathrm{Zu}$ sammenhanges von Wassertrübung, Transparenz und Seefarbe zur Diskussion. Die Resultate dieser Erhebungen und der im Laboratorium durchgefuihrten Versuche sind in der vorliegenden Arbeit zusammengestellt.

Wir danken der Direktion des Eidg. Amtes für Wasserwirtschaft für die Bewilligung, diese Ergebnisse im Druck herausgeben zu dürfen.

Zürich, den Io. Dezember I962.

Die Verfasser

\section{A. Allgemeines und theoretische Grundlagen}

Die allermeisten schweizerischen Gewässer, Flüsse, natürliche Seen und Stauseen, sind ausgezeichnet durch ein reines, klares Wasser, das den Wanderer einlädt zu wohltuender Rast und zum Bade, den Sportler zum Schwimmen, Rudern und Segeln und das einem reichen und vielgestaltigen. Fischbestand als Lebensraum dient. Die tiefblaue oder blaugrüne Farbe solcher über das ganze Land, über Ebene und Gebirge verteilter Gewässer erhöht überall den ästhetischen Reiz der Landschaft; vielhundertfach wird die Schönheit unserer Seen im vielsprachigen Liede besungen und mit Pinsel und Farbe im Bilde festgehalten.

Daneben können wir in unserm Lande auch Seen und Flüsse finden, deren Wasser dem Besucher nicht durchsichtig klar, sondern trübe, nicht blau oder blaugrün, sondern milchig oder gar grau bis braun, ja in noch auffallenderen Farben, wie rostrot oder zeitweise sogar blutrot, entgegen- 
tritt. Manche dieser Gewässer erfüllen sowohl den Naturfreund als auch den Wasserwirtschafter mit Sorge, weil sich in ihnen in neuerer Zeit eine ungünstige biologische Entwicklung vollzogen hat, die da und dort zu hässlichen Bildern an der Wasseroberfläche und längs der Ufer führte, in den tiefern Seebezirken aber Lebensverhältnisse schuf, die der Fischerei bereits zum Verhängnis wurden und die über kurz oder lang auch die Wasserbeschaffung der Ufergemeinden erschweren, wenn nicht verunmöglichen kann. Man spricht in solchen Fällen oft von «kranken» Seen und Fluissen.

Zwischen diesen beiden Extremen des biologischen Zustandes, einerseits des klaren Reinwassersees und anderseits des trüben, «kranken» Sees, liegt eine grosse Zahl von Gewässern, deren Regime zwar als gesund bezeichnet werden kann, deren Wasser aber nicht klar ist und nicht in seiner wirklichen Eigenfarbe erscheint, sondern das infolge seines hohen Gehaltes an suspendiertem, anorganischem Gesteinsmaterial (Schluff, Ton, Kolloidton) zeitweise oder andauernd trübe ist oder aber auffallende Färbungen aufweist, die auf Massenentfaltungen bestimmter Kleinorganismen sowohl aus dem Pflanzen- als auch aus dem Tierreich zurückzuführen sind. Die Bezeichnungen Milchsee, Schottensee, Grünsee, Blausee, Rot- oder Blutsee, Lago bianco, Lago scuro usw. gehen auf derartige Wasserfärbungen zurück.

Im folgenden sollen die theoretischen Grundlagen der Wassertrübung erörtert und im Anschluss daran unsere im Gelände aufgenommenen und im Laboratorium experimentell festgestellten Vorgänge zusammengestellt und diskutiert werden.

\section{Ursachen und Wirkung der Wassertruibung}

Als Trübungsstoffe kommen sowohl anorganische suspendierte Partikeln von verschiedener chemischer Beschaffenheit, Grösse und Form als auch Organismen von kleinen bis kleinsten Ausmassen in Frage, die in massenhaftem Auftreten ein Wasser trüben, ja beinahe undurchsichtig machen können.

Enthält eine Flüssigkeit Teilchen, deren Durchmesser mehr als I $\mu \mu$ (10-6 $\mathrm{mm}$ ) und weniger als $\mathrm{O}, \mathrm{I} \mu$ beträgt, so wird einfallendes Licht in dieser Lösung gestreut (Tyndalleffekt). Die Fliissigkeit besteht in diesem Falle aus einem Dispersionsmittel (Wasser) und dem dispergierten Stoff. In einer kolloiden Lösung erreicht die Gesamtoberfläche der Teilchen enorme Ausmasse. Die Physik lehrt uns, dass die freie Oberflächenenergie

$$
d F=\sigma \cdot d O
$$


einem Minimum zustrebt, so dass die Oberflächenspannung eines Körpers bestrebt ist, dessen Oberfläche zu verkleinern. Die Oberflächenspannung eines Teilchens wirkt also der Dispersionsbildung entgegen. Elektrostatische Abstossung gleich geladener Teilchen und Lyophilie (Hydratation bei Wasser als Dispersionsmittel) wirken der oberflächenverkleinernden Kraft entgegen. Die Stabilität kolloider und grobdisperser $(>0, \mathrm{I} \mu)$ Systeme (letztere empfindet auch das menschliche Auge als getruibte Lösung) hängt weitgehend von der ionalen Zusammensetzung inklusiv $\mathrm{pH}$ des Dispersionsmittels ab. Kolloide Lösungen können in einen Flokkungszustand gebracht werden, wenn die Ladung der dispergierten Teilchen unter einen gewissen Schwellenwert (kritisches Potential) sinkt.

Die meisten unserer alpinen Seen und besonders unsere in den Bergen entspringenden Bäche und Flüsse sind vorwiegend durch anorganische Gesteinspartikel getrübt, handle es sich dabei um unverändertes Muttergesteinsmaterial, angewitterte Mineralien des Muttergesteins oder um neugebildete Mineralien (Tonmineralien).

Da nun der Grad der Trübung vom Gehalt an den im Wasser schwebenden oder langsam absinkenden Teilchen abhängt, kann jener aus diesem letzteren angenähert errechnet werden. Dabei gilt als Grundlage die «Schwebetheorie» WESENBERG-LUNDS, die von WOLFGANG OSTWALD erweitert und auf folgende Formel gebracht wurde:

$$
\text { Sinkgeschwindigkeit }=\frac{\text { Ubergewicht }}{\text { Formwiderstand } \cdot \text { innere Reibung }} .
$$

Dabei bedeutet Übergewicht den Unterschied zwischen dem Gewicht des «schwebenden» Körpers und demjenigen des von ihm verdrängten, umhüllenden Mediums (des Wassers als Dispersionsmittel). Das Produkt aus Formwiderstand und innerer Reibung ist der Ausdruck des Widerstandes, den der absinkende Körper zu überwinden hat, wobei der Formwiderstand vornehmlich durch zwei Grössen gekennzeichnet ist, nämlich durch die spezifische Oberfläche (Verhältnis der Gesamtoberfläche zum Volumen) und die Projektionsgrösse (auf eine zur Bewegungsrichtung senkrechte Ebene). Die innere Reibung ist abhängig von der Zähigkeit und damit von der Temperatur des Wassers. Welch hohe Bedeutung dieser letzteren für die Sinkgeschwindigkeit der Suspensa zukommen muss, geht beispielsweise daraus hervor, dass die Zähigkeit des Wassers bei $0^{\circ} \mathrm{C}$ rund doppelt so gross ist wie bei $25^{\circ} \mathrm{C}$.

Vereinfacht man die Voraussetzungen durch Vernachlässigung von Faktoren, indem man z. B. die Fallgeschwindigkeit berechnet unter der 
Annahme, dass die sinkenden Teilchen kugelförmig wären, so lässt sich die bekannte Stokessche Formel

$$
\text { Sinkgeschwindigkeit } p=\frac{2 g r^{2}\left(D-D_{0}\right)}{9 \eta}
$$

anwenden, wobei $D$ die Dichte des in Suspension befindlichen Körpers, $D_{0}$ die Dichte des Dispersionsmittels und $\eta$ seine innere Reibung bedeuten. Ist experimentell die Sinkgeschwindigkeit festgestellt, so kann aus ihr der sog. Äquivalentradius ermittelt werden, d. h. der Radius, den kugelförmige Teilchen von derselben Sinkgeschwindigkeit hätten.

Dabei muss freilich angenommen werden, dass das Dispersionsmittel, d. h. in unserm Falle Wasser, unbewegt, also von innern Strömungen, Wirbelbildungen usw. frei ist, was in natürlichen Gewässern wegen der Temperaturunterschiede in vertikaler wie auch in horizontaler Richtung wohl nie ganz der Fall sein wird.

Blöcke mit einem Äquivalentradius $>200 \mathrm{~mm} \varnothing$ und Grobkies $(200-20 \mathrm{~mm} \varnothing)$, um der Atterbergschen Korneinteilung zu folgen, werden je nach Strömungsgeschwindigkeit in den Quellgebieten liegen gelassen, während Feinkies $(20-2 \mathrm{~mm} \varnothing)$ und Grobsand $(2-0,2 \mathrm{~mm} \varnothing)$ oft bis in unsere Voralpenseen mitgerissen werden. Feinsand mit einem Korndurchmesser von $0,2-0,02 \mathrm{~mm}$ und einer Sinkgeschwindigkeit bis $0,3 \mathrm{~mm} / \mathrm{sec}$ befindet sich nebst feineren Fraktionen in den meisten Sedimenten unserer Voralpenseen. Feinere Teilchen, wie Schluff $(0,02-0,002$ $\mathrm{mm} \varnothing)$ und Ton $(<0,2 \mu)$, weisen vielstündige bis tagelange Sedimentationszeiten auf und verleihen im allgemeinen den Wässern die uns bekannte, lange anhaltende und mit Papierfiltern kaum filtrierbare «Trübe». Tone treten in ihren feinsten Körnungen kolloid als Kolloidton auf. Die ionale Zusammensetzung der Wässer bestimmt, wie bereits angetönt, die Stabilität solcher kolloiden Systeme. Grössere Seen sind in ihrer chemischen Natur oft anders beschaffen als ihre Trübungsstoffe führenden Zuflüse, und es ist denkbar, dass Tone, die im Zufluss eine relativ sehr lange Sinkzeit erfordern würden, im See dank anderer pH-Verhältnisse (insbesondere bei $\mathrm{pH}$ 8) durch Flockung zur rascheren Sedimentation gelangen.

Neben diesen anorganischen Trübstoffen sind die nichtbelebten organischen Teilchen zu nennen, die in kolloidaler Form als Humussäuren vom Wasser gelöst wurden und durch Entladung in einen feinen Flockungszustand übergegangen sind. Daneben treten als organische, suspendierte Stoffe kleine bis kleinste in Verwesung begriffene Pflanzenteilchen auf.

Zur andern grossen Gruppe der Trübstoffe gehören die Planktonorganismen, die in unterschiedlicher Dichte oft zu Zehn- bis Hunderttausenden 
Hydrol.

im Liter Seewasser auftreten können und unter denen hinsichtlich der Trübungswirkung die fädige Alge Oscillatoria rubescens wohl eine besondere Stellung einnehmen dürfte. Viele Planktonorganismen wirken durch aktive Bewegung ihrer Sedimentation entgegen.

\section{Die Wasserfarbe unserer Seen}

Die Farbe eines Sees ergibt sich als Resultierende mehrerer optischer Effekte, die beim Bestrahlen eines Sees durch direktes Sonnenlicht und durch diffuse Himmelsstrahlung auftreten.

Die auf eine Wasserfläche einfallenden Strahlen werden teilweise durchgelassen und teilweise reflektiert. Für die Reflexion einer ruhenden Wasserfläche gilt theoretisch die Formel von FrESNEL

$$
R=1 / 2 \cdot \frac{\sin ^{2}(i-r)}{\sin ^{2}(i+r)}+\frac{\operatorname{tg}^{2}(i-\gamma)}{\operatorname{tg}^{2}(i+\gamma)},
$$

wobei $i$ den Einfallswinkel und $r$ den Brechungswinkel bedeuten. Nach RUTTNER beträgt die Reflexion in unsern Breiten mittags im Mittel während des Sommers $2,5 \%$ und im Winter $14 \%$. Von der diffusen Himmelsstrahlung, welche 8-100\% der Gesamtstrahlung ausmachen kann, werden etwa $6 \%$ unabhängig von der Wellenlänge reflektiert.

Der ins Wasser eintretende Strahlungsanteil wird an den Molekuilen und suspendierten Teilchen gestreut, der Rest bei der Absorption in Wärme umgewandelt.

Die Intensität der Gesamtstrahlung nimmt nach der bekannten Exponentialfunktion

$$
I_{x}=I_{o} e^{-E h}
$$

$\mathrm{ab}$, wobei $I_{x}$ die Intensität in der Tiefe $x, I_{0}$ in der Tiefe $\circ \mathrm{m}, E$ den Absorptions- oder Extinktionskoeffizienten und $b$ die Weglänge der Strahlen bis in die Tiefe $x$ bedeuten. Der Anteil an nichtabsorbierter Strahlung wird Transmission, der absorbierte Anteil Extinktion genannt. Zur Messung der Gesamtstrahlung verwendeten SUCHLANDT und SCHMASSMANN für 8 Hochgebirgsseen Insolationsthermometer und das Eder-Hechtsche Graukeilphotometer, während BIRGE und JUDAY ihre Messungen mittels Thermosäulen durchführten. Im Lunzer Obersee (25. Februar 1938) wurden bis $5 \mathrm{~m} \mathrm{90 \%} \mathrm{Lichtdurchlässigkeit,} \mathrm{in} \mathrm{II} \mathrm{m}$ noch $50 \%$ und in $\mathrm{I} 4 \mathrm{~m}$ nur noch $10 \%$ gemessen, während BIRGE und JUDAY im Seneca Lake (I. August I9r8) in $5 \mathrm{~m}$ nur noch rund $5 \%$, in to $m$ noch $\mathrm{r} \%$ der Gesamtstrahlung vorfanden. 
Extinktion und Transmission sind für die verschiedenen Spektralbereiche von der Wellenlänge abhängig. Die spektrale Durchlässigkeit kann mittels panchromatischer Filme unter Wrattenfiltern und Sperrschichtphotozellen untersucht werden. Seewasser verhält sich hinsichtlich der Durchlässigkeit verschiedener Wellenlängen sehr abweichend von doppelt destilliertem Wasser. Optisch leeres Wasser (= Wasser, welches keinen Tyndalleffekt zeigt) absorbiert einfallendes Licht in geringem Masse. Je kürzer die Wellenlänge der sichtbaren Strahlung, um so weiter dringen die Lichtquanten vor. In genügend grosser Tiefe aber wird auch im optisch leeren Wasser sämtliches einfallende Licht schliesslich absorbiert, und ein See mit optisch leerem Wasser müsste aus diesem Grunde schwarz erscheinen. Nun kennen wir aber keine natürlichen Gewässer, die optisch leer genannt werden könnten. Jedes Wasser, auch das reinste Quell- und Grundwasser, enthält chemische Stoffe in Lösung, deren Moleküle und Ionen das Licht absorbieren, reflektieren und streuen.

Untersuchungen von AUFSESS, SAUBERER, SUCHLANDT und SCHMASSMANN zeigten, dass in den natürlichen Gewässern die Transmission für grüne und blaue Strahlen am grössten ist und sowohl für Farben mit kleineren als auch grösseren Wellenlängen abnimmt.

Bei einem klaren Gewässer wird demnach die Seefarbe weitgehend von der Lichtfilterwirkung des Wassers als Folge seines Gehaltes an echt und kolloidal gelösten Stoffen abhängig sein und mit zunehmender Klarheit einen Farbton von Dunkelgrün gegen Dunkelblau aufweisen. Suspendierte Teilchen bewirken durch ihre Lichtreflexion Aufhellung und können in extremen Fällen den Seen ein milchiges Aussehen verleihen. Braune Töne als Folge relativ hohen Humussäurengehaltes des Wassers kommen in unsern Gewässern nur selten vor, während sie inden grossen Moorgebieten Nordeuropas dominieren.

Eutrophe Seen neigen ausserdem zu ausgesprochenen Vegetationsfärbungen. Peridineen-Massenentwicklungen verleihen einem Gewässer eine hellgraue Farbe (Muzzanersee). Euglena sanguinea vermag eutrophe Kleingewässer, die besonders in den Alpweiden der alpinen Stufe häufig sind, in «Blutseen» zu verwandeln, eine Eigenschaft, die im Mittelland auch Oscillatoria rubescens zukommt. Anabaena- und Microcystisarten und in allerneuester Zeit auch Apbanizomenon flos-aquae bedecken unsere Gewässer zur Zeit ihrer Massenentfaltung nicht selten mit einem satten, leuchtenden Blaugrün. 


\section{B. Methodik}

\section{Trübungsmessung}

Das zur Prüfung gefasste Wasser wird in einem Becherglas vom Innendurchmesser $36 \mathrm{~mm}$ oder bei grösseren Trübungen in einer Küvette von $2,5 \mathrm{~mm}$ Schichtdicke in die mit destilliertem Wasser gefüllte Wasserkammer gestellt. In diese fällt durch eine optische Linse das Licht einer Lampe von $60 \mathrm{~K}$ in Form eines parallelen Bündels von quadratischem Querschnitt und verlässt die Wasserkammer durch eine weitere Linse unter einem Winkel von $45^{\circ}$ zur Einfallsrichtung. Ein Teil des Lichtes wird vor Eintritt in die Wasserkammer gespiegelt und geht durch Mattscheiben von abgestufter Lichtdurchlässigkeit. Beide Strahlengänge werden nun durch das Pulfrich-Stufenphotometer betrachtet. Dieses besteht in optischer Hinsicht aus einem Doppelfernrohr; durch das eine der Fernrohre wird das aus der Wasserkammer austretende Licht, durch das andere das Vergleichslicht betrachtet. Beide Strahlengänge werden durch ein Prismensystem einem gemeinsamen Okular in der Weise zugeführt, dass das Licht des einen Fernrohrs die eine, das des andern die andere Hälfte des durch eine feine Trennungslinie geteilten Gesichtsfeldes beleuchtet. Die Einstellung auf gleiche Helligkeit geschieht durch Blenden, die an den Öfnungen des Photometers angebracht sind. Durch diese Messung wird also die Konzentration an trübender Substanz des Untersuchungswassers bestimmt. Der erhaltene Wert ist ein relativer. Um die Konzentration in einem absoluten Wert angeben zu können, bedarf es eines auf ein absolutes Trübungsmass geeichten, festen Trübungskörpers, der dem Trübungsmesser beigegeben ist. Als Einheit der Trübung wird das Verhältnis der beobachteten Helligkeit zu derjenigen Helligkeit gegeben, die man beobachten müsste, wenn das gesamte eingestrahlte Licht gestreut würde, unter der Voraussetzung, dass die lichtstreuende Schicht eine Tiefe von I $\mathrm{cm}$ in der Beobachtungsrichtung besitzt und der Winkel zwischen Beobachtungs- und Beleuchtungsrichtung $45^{\circ}$ beträgt. Eine Umrechnung jeglicher Trübung in das oben definierte Mass ist mit Hilfe folgender Formel möglich:

$$
T_{a b s}=\frac{r e l . T r}{H} \cdot d \cdot t .
$$

$T_{a b s} \quad$ absolute Trübung

$r e l$. $T r$. Helligkeit der Trübungsflüssigkeit

$H \quad$ Helligkeit des Trübungsprismas ( $r e l . T r$. $)$

d bekannter Faktor für Fassungsgläser

$t \quad$ Trübungswert des Trübglaskörpers $(t=0,0272)$ 
Die in unseren im folgenden beschriebenen Untersuchungen angegebenen'Trübungswerte stellen also absolute Werte dar; sie sind deshalb untereinander vergleichbar.

\section{Transparenzmessung}

Schon in den Anfängen limnologischer Forschung wurde, insbesondere durch F. A. Forel (Le Léman I892-1904), der Sonnen- und Himmelsstrahlung in einem See beträchtliches Interesse gewidmet. Ein gebräuchliches Verfahren wurde gefunden in der Anwendung einer weissgestrichenen, runden Scheibe von $30 \mathrm{~cm}$ Durchmesser, der sog. «Secchischeibe», welche im Bootsschatten so weit versenkt wird, bis sie eben dem Auge entschwindet. Die in diesem Moment abgelesene Tiefe bezeichnet man als Sichttiefe und nimmt sie als Mass für die Durchsichtigkeit oder Transparenz eines Gewässers. Sie ermöglicht eine grobe Orientierung über die Lichtverhältnisse in einem Wasser, gibt aber keinen Aufschluss über die spektrale Durchlässigkeit desselben. Diese Bestimmungsmethode wird heute in allen Ländern angewendet, wo limnologische Untersuchungen durchgeführt werden.

\section{Beurteilung der Eigenfarbe eines Sees}

Die Farbe des Wassers kann auf verschiedene Weise festgestellt werden. Im Laboratorium wird sie ermittelt, indem Wasser in ein oben und unten mit Glasplatten verschlossenes Rohr von $5-6 \mathrm{~m}$ Länge eingefüllt und im durchfallenden Licht betrachtet wird.

Gebräuchlicher aber ist die Methode der Feststellung mit Hilfe des unbewaffneten Auges. Man geht dabei so vor, dass man an einer Stelle, wo der Gewässergrund nicht sichtbar ist, unter Ausschluss aller Spiegelungseffekte im Bootsschatten in die Tiefe schaut und die Farbe an Hand einer standardisierten Farbenskala ermittelt.

Eine derartige Skala, speziell für den Gebrauch des Limnologen, wurde von FOREL aufgestellt und von ULE erweitert und umfasst in 2I Stufen den Farbenbereich natürlicher, also blauer, grüner und brauner Seen. Die höhern Farbstufen kommen für schweizerische Gewässer nur selten zur Anwendung.

Indessen sind die Farbtöne unserer Gewässer weit feiner abgestuft als diese Farbenskala. Um auch mittlere Farbtöne festhalten zu können, griffen wir auf unsern Exkursionen zur internationalen Farbenskala von SEGUY, die wir stets mit uns führten. Schliesslich setzten wir die auf diesem Wege gewonnenen Werte noch mit denen der Forel-Uleschen Skalen in Beziehung. 
4. Gruppierung der untersuchten Gewässer nach ihrem mittleren Trübungswert

Die recht umfangreichen Ergebnisse der Trübungsmessungen, die in den Jahren I944-195I aus Einzel- und Daueruntersuchungen gesammelt werden konnten, ergaben nicht nur beträchtliche Unterschiede in den Werten zwischen den verschiedenen Seen und Flußsystemen, sondern auch ansehnliche Schwankungen innerhalb gleicher Gewässer, insbesondere in Abhängigkeit von der Wassertiefe und der Jahreszeit.

Trotz dieser Schwankungen klassiert das menschliche Auge die Oberflächenwässer in «klare», "getrübte» und «trübe» Seen und Fliesswässer, Kategorien, die indessen durch alle Übergänge miteinander verbunden sind.

Im folgenden geht es nun darum, die aus unseren Messungen hervorgegangenen Werte mit der Klassifizierung durch das unbewaffnete Auge in Beziehung zu bringen. Ein diesbezüglicher Vergleich begegnet indessen insofern nicht geringen Schwierigkeiten, als die Trübung durch unterschiedliche und voneinander unabhängige Faktoren verursacht wird. Anorganische Suspensa (Gletschertrübe) und organische Schwebeteilchen im Wasser (Planktonorganismen) können den Grad der Trübung in recht massgeblicher Weise beeinflussen.

Um schon zum voraus die Grundlage für eine Diskussion unserer Ergebnisse zu schaffen, sollen die untersuchten Seen gemäss ihrem mittleren Trübungswert klassiert werden in:

a) Klarmasserseen: Ihre mittlere Trübung (Mittelwert aus möglichst zahlreichen, $\mathrm{zu}$ verschiedenen Jahreszeiten und auch in verschiedenen Wassertiefen festgestellten Werten) soll $\mathbf{I 2} \cdot \mathrm{IO}^{-4}$ (absoluter Trübungswert) nicht übersteigen. Solchen Verhältnissen dürfte eine Transparenz (ermittelt mit der Secchischeibe) von mehr als $5 \mathrm{~m}$ entsprechen. Die Farbe der Klarwasserseen ist klarblau bis klarblaugrün.

b) Mitteltrübe Seen: Die Mittelwerte der Trübung liegen zwischen $\mathrm{I} 2 \cdot \mathrm{IO}^{-4}$ und $5 \mathrm{O} \cdot \mathrm{IO}^{-4}$, die Transparenz zwischen 5 und $\mathrm{I} \mathrm{m}$. Die Seefarbe wechselt im allgemeinen von Blaugrün über Grün, evtl. Schmutziggrün, nach Milchiggrün.

c) Trübe Seen: Thre mittlere Trübung ist höher als $50 \cdot 10^{-4}$ und kann Werte bis $680 \cdot \mathrm{IO}^{-4}$, eventuell sogar noch mehr, erreichen. Die Transparenz ist kleiner als I m. Als Farbe ist Milchighellgrün bis Milchigweiss (Gletscherseen), Braunrot (Oscillatoriaseen), Blutrot (Blutseen) oder Graugrün (Peridineenseen) zu erwarten. 
Bezüglich der Wassertrübung kann sich ein See im Laufe der Jahreszeiten (Schneeschmelze, Regenperioden, Platzregen, gesteigerte Planktonentwicklung usw.) in einem weiten Ausmasse und mehr oder weniger periodisch verändern. In solchen Fällen sind neben den Jahresmittelwerten auch diejenigen einzelner Jahreszeiten in Betracht zu ziehen.

Sind in den nachstehenden Tabellen ausser den Werten, die sich aus Serienuntersuchungen ergaben, auch die Ergebnisse von Einzelbestimmungen berücksichtigt worden, so handelt es sich dabei um Zahlen, die entweder aus zahlreichen Beobachtungen erfahrungsgemäss als plausibel erscheinen oder als Maximalwerte angesehen werden können, z. B. solche aus Mitte bis Ende der Sommerstagnation, aus einer Zeit also, in der die Planktonentwicklung bereits das Maximum ihrer Entfaltung erreicht hatte.

So wie ein eutropher See zu gewissen Zeiten nährstoffarm werden kann, erscheint ein normalerweise mitteltrüber See zeitweise als Klarsee. In solchen Fällen sind neben den Jahresmittelwerten diejenigen einzelner Jahreszeiten zu berücksichtigen.

In Tab. I sind die Trübungswerte von 30 Schweizer Seen nach der oben angeführten Gliederung zu finden.

In Tab. 2 sind Trübungswerte verschiedener fiessender Gewässer zusammengestellt und nach steigenden Werten geordnet. Die Resultate entsprechen indes nicht Durchschnittswerten der betreffenden Gewässer, sondern stellen lediglich vergleichbare Werte aus einer relativ niederschlagsarmen Beobachtungsperiode dar. Anderseits sind verschiedenen gemessenen Werten die visuellen Beurteilungen beigefügt. Die Erfahrung hat gezeigt, dass man Wasser aus Klarseen und aus klaren Fliessgewässern, welches die gleichen Trübungswerte besitzt, von Auge ungefähr gleich beurteilt, während man das Wasser aus einem nach Messung mitteltriben See visuell, das heisst, in die Beurteilungsskala der Fliessgewässer eingestuft, als «ziemlich trüb», Wasser aus einem trüben See als «stark trüb» beurteilen würde.

\section{Zusammenhang zwischen Trübung, Transparenz und Seefarbe}

Wie im theoretischen Teil der vorliegenden Arbeit ausgeführt wurde, ist die Strahlentransmission im Wasser weitgehend von der Trübung abhängig. Anderseits stehen Sichttiefe und Strahlengang in gegenseitiger Beziehung. Deshalb müssen auch Trübung und Transparenz in einer gewissen Korrelation stehen. 
Tabelle 1

Mittlere Trübungen perscbiedener Scbweizer Seen, nach steigendem Trübungswert geordnet

Versuch einer Gliederung:

"Klarseen"

"Mitteltrübe Seen"

Tabs $12 \cdot 10^{-4}$

"Trübe Seen"

$T_{a b s} 12-50 \cdot 10^{-4}$

$T_{a b s} 50 \cdot 10^{-4}$

Transparenz $5 \mathrm{~m}$

Transparenz 1-5 m

Transparenz $0-1 \mathrm{~m}$

Klarseen

Langensee (14.8.46 u. 29.7.46)

Lago Nero, Bernina (23.9.46)

Partnunersee, Prättigau (9. 8.46)

Engstligensee (22.9.46)

Gotthardpaßseen (13.8.46)

Lago Ritom (18.9.46) Weitere Pioraseen: Lago Cadagno, Lago Tom, Lago Scuro, Lago
Taneda (18. 8. 46)

Lac de Neuchâtel (25.8.46)

Oberer Schwendisee, Toggenburg (11. 8. 46)

Unterer Glunersee, Prätigau (8. 8. 46)

Lac Léman bei Ouchy (27. 8. 46)

$T_{a b s}$ Mittel

$4,0 \cdot 10^{-4}$

$5,5 \cdot 10^{-4}$

$6,6 \cdot 10^{-4}$

$6,6 \cdot 10^{-4}$

$6,8-7,4 \cdot 10^{-4}$

$7,3 \cdot 10^{-4}$

$6,9-8,3 \cdot 10^{-4}$

$8,1 \cdot 10^{-4}$

$8,2 \cdot 10^{-4}$

$8,4 \cdot 10^{-4}$

$12,3 \cdot 10^{-4}$

Mitteltrübe Seen

Sihlsee, 13 Probenahmen (1946-1951)

Unterer Schwendisee, Toggenburg (11.8.46)

St.-Moritzer-See (23, 9. 46)

Ägerisee (25.8.46)

Untersee, 6 Probenahmen (1944)

Lac de Barberine (25. 8. 46)

Lungernsee, 5 Probenahmen (1944-1945)

Zürcher Obersee, 5 Probenahmen (1944-1945)

Lago di Poschiavo (22.9.46)

Gelmersee (28. 8. 46)

Hallwilersee, 7 Probenahmen (1944-1945)

Wägitalersee, 8 Probenahmen (1944-1945)

Trübe Seen

Lago Bianco (23. 9.46)

Muzzanersee (bei Lugano)

Rootsee (25.8.46)

Grimselsee (13.8. und 23. 7. 46)
$13,1 \cdot 10^{-4}$

$13,2 \cdot 10^{-4}$

$13,4 \cdot 10^{-4}$

$13,6 \cdot 10^{-4}$

$13,8 \cdot 10^{-4}$

$16,5 \cdot 10^{-4}$

$19,5 \cdot 10^{-4}$

$24,1 \cdot 10^{-4}$

$24,8 \cdot 10^{-4}$

$36,4 \cdot 10^{-4}$

$37,5 \cdot 10^{-4}$

$39,7 \cdot 10^{-4}$

$124 \cdot 10^{-4}$

$216 \cdot 10^{-4}$

$271 \cdot 10^{-4}$

$685 \cdot 10^{-4}$

Aus der Kompliziertheit der optischen Effekte, die sich beim Durchgang von Strahlen durch getrübte Medien ergeben, ist die Abhängigkeit zwischen Trübung und Transparenz nur schwer zu erkennen, was sich im Versuch einer Auswertung unserer Trübungs- und Transparenzmesswerte bestätigt.

Bei dieser Auswertung erscheint es als zweckmässig, die untersuchten Seen nach der Art ihrer Trübungsstoffe einzuteilen, I. in Seen, deren Wasser vorwiegend durch anorganische Schwebestoffe getrübt wird, z. B. Gletschertrübe, 2. in solche mit einer verhältnismässig schwach 
Tabelle 2

Trübung fliessender Gewässer wäbrend der niederschlagsarmen Periode Mitte Fuli bis Ende September 1946

\begin{tabular}{|c|c|c|c|}
\hline Gewässer & Datum & $\begin{array}{l}T_{a b s} \\
\cdot 10^{-4}\end{array}$ & $\begin{array}{l}\text { Visueller } \\
\text { Befund }\end{array}$ \\
\hline Quellbach bei Nufenen (Hinterrhein) & 6.10 .46 & 2,8 & klar \\
\hline Capellabach bei Nufenen & 6.10 .46 & 3,4 & klar \\
\hline Ova del Bernina (Passhöhe) & 22.9 .46 & 5,6 & klar \\
\hline Aare bei Bern & 24.8 .46 & 7,5 & klar \\
\hline Rhein bei Schaffhausen & 9. 8.46 & 11,1 & \\
\hline Simme oberhalb Stauung & 24.8 .46 & 11,2 & leicht getrübt \\
\hline Hallwilerseeabfluss & 25.9 .46 & 12,0 & \\
\hline Poschiavina von Puschlaverseemündung & 22.9 .46 & 12,2 & \\
\hline Kander & 24.8 .46 & 13,3 & ziemlich trüb \\
\hline Engelbergeraa vom Ausgleichsbecken & 14.9 .46 & 13,5 & \\
\hline Inn bei Samedan & 9.8 .46 & 16,1 & \\
\hline Broye bei Salavaux & 25.8 .46 & 16,6 & \\
\hline Rhein bei Buchs & 31.7 .46 & 19,7 & \\
\hline Vorderrhein bei Ilanz & 30.7 .46 & 20,4 & \\
\hline Hallwilerseeeinfluss von Mosen & 26.9 .46 & 21,8 & \\
\hline Albula bei Sils i. $\mathrm{D}$. & 30.7 .46 & 22,4 & \\
\hline Ticino bei Piotta Centrale & 19.8 .46 & 23,1 & \\
\hline Vorderrhein ob Reichenau & 30.7 .46 & 25,4 & \\
\hline Lütschine bei Bönigen & 24.8 .46 & 25,8 & ziemlich trüb \\
\hline Rhein bei Ems & 30.7 .46 & 26,4 & \\
\hline Glenner: & 30.7 .46 & 37,8 & \\
\hline Reuss bei Altdorf & 24.8 .46 & 41,2 & \\
\hline Nolla bei Thusis & 30.7 .46 & 42,9 & \\
\hline Rhone bei Martigny & 24.8 .46 & 108,5 & \\
\hline Aare bei Brienz & 24.8 .46 & 147 & stark trüb \\
\hline Ova del Bernina vor Innmündung & 23.9 .46 & 272 & \\
\hline Hauptzufluss zum Lago Bianco & 22. 9.46 & 278 & \\
\hline Oberaarbach vom Grimselsee & 13. 8.46 & 463 & \\
\hline Abfluss des Morteratschgletschers & 22.9 .46 & 582 & \\
\hline Abfluss des Unteraargletschers & 23. 7.46 & 1048 & \\
\hline
\end{tabular}

entfalteten Planktonproduktion, in denen es also nicht zu ausgesprochenen Wasserblüten kommt (Oscillatoria-freie oder -arme Seen), und 3. in Seen mit ausgesprochenen Wasserblüten, unter denen (insbesondere im Herbst und Frühjahr zur Zeit der Teil- und Vollzirkulationsperioden) die Burgunderblutalge in den oberflächlichen Wasserschichten zu starker Entfaltung gelangt. Indessen sind auch zahlreiche andere Planktonorganismen imstande, auffallende Wasserblüten auszubilden (Microcystis aeruginosa, Mougeotia sp., Anabaena flos-aquae, Apbanizomenon flos-aquae, seit $1960 \mathrm{z}$. B. neu).

Die folgenden graphischen Darstellungen und Tabellen zeigen $z$. $T$. die einzelnen Trübungswerte des Wassers an der Seeoberfläche und z. T. die Mittelwerte aus den in der Untersuchung berücksichtigten Tiefenstufen 


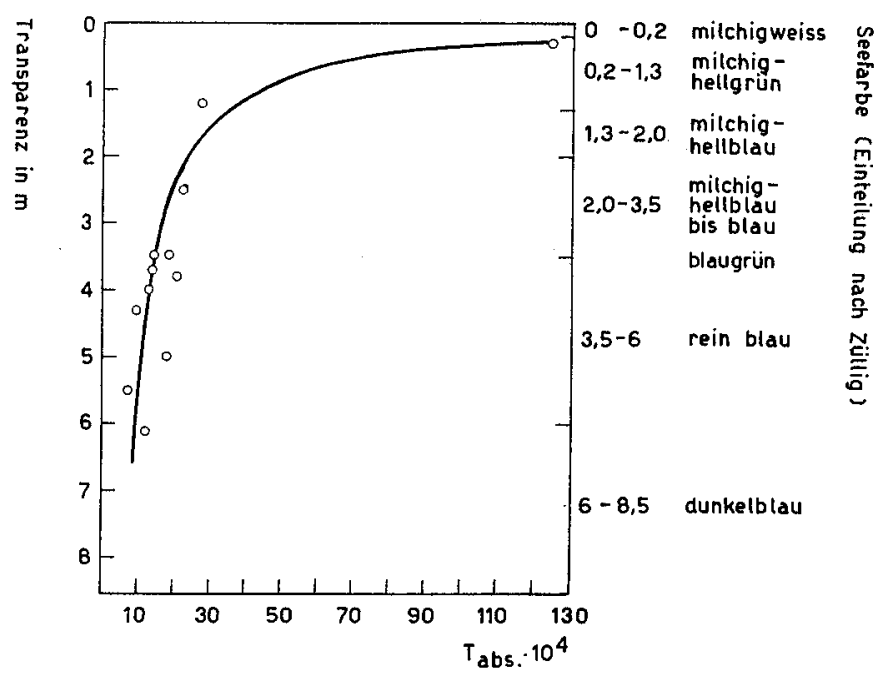

Abbildung 1

Zusammenhang zwischen Seefarbe, Transparenz und Trübung, verursacht durch anorganische, suspendierte Stoffe.

von o- $5 \mathrm{~m}$. In Abb. I und Tab. 3 wurden 7 Seen ausgewählt, deren Wasser durch vorwiegend anorganische Schwebestoffe getrübt wird. Die in ihnen festgestellten Trübungswerte durchlaufen eine Skala von weniger als IO $\cdot \mathrm{IO}^{-4}$ bis gegen $130 \cdot \mathrm{IO}^{-4}$ (Der Einfachheit halber ist in den folgenden Trübungsangaben der Faktor IO $^{-4}$ weggelassen; siehe Beschreibung der Methodik auf Seite 8.). Diese Werte sind auf der Abszisse aufgetragen, während auf der Ordinate die zugehörigen Werte der Transparenz berücksichtigt sind. Aus dieser Zusammensetzung ergibt sich, dass die Transparenz mit zunehmendem Trübungswert abnimmt, und zwar nicht linear, sondern exponentiell. Bis zu Trübungswerten von etwa 20 nimmt die Durchsichtigkeit einigermassen linear $a b$; bei höheren Werten, die etwa zwischen 20 und 60 liegen mögen, ist die Verminderung bereits wesentlich geringer. Diese Trübungen entsprechen einer Transparenz von etwa 3 bis I m. Um aber die Sichttiefe weiterhin zu vermindern, bedarf es bereits einer beträchtlichen Erhöhung der Trübung. Dem Wert von 127 entspricht beispielsweise eine Transparenz von $0,3 \mathrm{~m}$.

Noch schwieriger gestaltet sich die Feststellung der Zusammenhänge zwischen Seefarbe, Transparenz und Trübung.

Bei Seen, die durch suspendiertes, anorganisches Material getrübt werden, in unserm Gebiet vorwiegend hochalpinen Seen, hat H. ZüLLIG 
zwischen Seefarbe bei maximalem Sonnenstand und maximaler Transparenz folgenden Zusammenhang feststellen können:

$\begin{array}{ll}\text { Transparenz } & \text { Seefarbe } \\ 0,0-0,2 \mathrm{~m} & \text { milchigweiss } \\ 0,2-1,3 \mathrm{~m} & \text { milchighellgrün } \\ 1,3-2,0 \mathrm{~m} & \text { milchighellblau } \\ 2,0-3,5 \mathrm{~m} & \text { milchighellblau bis blau } \\ 3,5-6,0 \mathrm{~m} & \text { rein blau } \\ 6,0-8,5 \mathrm{~m} & \text { dunkelblau }\end{array}$

Die Wasserfarbe durch Plankton getrübter Seen zur Transparenz und zur Trübung in Beziehung zu setzen, stösst deshalb auf beträchtliche Schwierigkeiten, weil neben der aus der Trübung an sich resultierenden Wasserfarbe die Eigenfarbe des Planktons, die sog. «Vegetationsfärbung», mit eine Rolle spielt. Der letztere Faktor liesse sich in manchen Fällen dann eliminieren, wenn unsere Gewässer auch in dieser Hinsicht wiederum nach ihrer Planktonzusammensetzung klassiert würden. Zurzeit genügen aber unsere Erhebungen nicht, um für verschiedene nach ihrem Plankton differenzierte Seetypen den Zusammenhang zwischen Seefarbe, Transparenz und Trübung auch nur angenähert zu ermitteln.

In Abb. 2 sind die mittleren Werte der Trübung und Transparenz aus Seen zusammengestellt, die während einer längeren Periode unter-

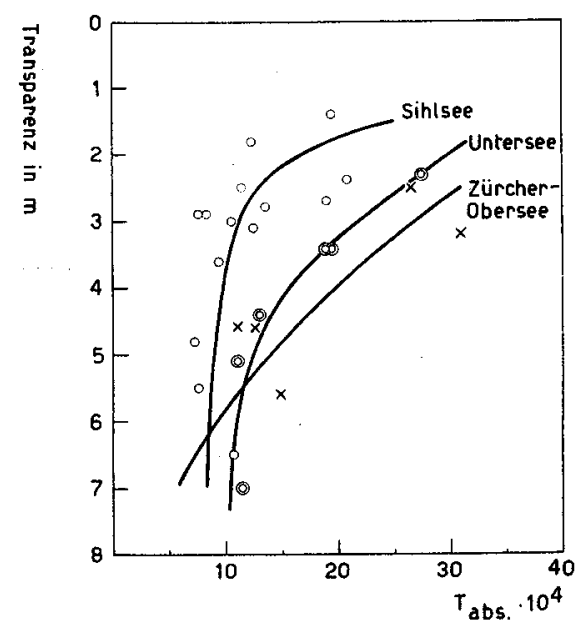

Abbildung 2

Zusammenhang zwischen Transparenz und Trübung, verursacht durch Oscillatoria-freies bis Oscillatoria-armes Plankton. 
Tabelle 3

Trübungs- und Transparenzmessungen an perscbiedenen Schpeizer Seen

\begin{tabular}{llcl} 
Gewässer & Datum & $T_{a b s}$ & $\begin{array}{l}\text { Trans- } \\
\text { parenz } \\
\text { in } \mathrm{m}\end{array}$ \\
\hline
\end{tabular}

Durch vorwiegend anorganische Schwemmstoffe getrïbte Seen

$\begin{array}{lrrr}\text { Brienzersee } & 24.8 .46 & 27,4 \cdot 10^{-4} & 1,2 \\ \text { Thunersee } & 24.8 .46 & 7,4 \cdot 10^{-4} & 5,5 \\ \text { Lago Bianco } & 22.9 .46 & 124,0 \cdot 10^{-4} & 0,3 \\ \text { Sarnersee } & 24.8 .46 & 10,2 \cdot 10^{-4} & 4,3 \\ \text { Ägerisee } & 25.8 .46 & 13,6 \cdot 10^{-4} & 4,0 \\ \text { Silsersee } & 23.9 .46 & 18,7 \cdot 10^{-4} & 3,5 \\ \text { Lungernsee } & 24.8 .46 & 14,0 \cdot 10^{-4} & 3,5 \\ \text { Lungernsee } & 7.5 .44 & 22,6 \cdot 10^{-4} & 2,5 \\ \text { Lungernsee } & 18.6 .44 & 18,1 \cdot 10^{-4} & 5,0 \\ \text { Lungernsee } & 22.10 .44 & 12,2 \cdot 10^{-4} & 6,1 \\ \text { Lungernsee } & 24.3 .45 & 21,0 \cdot 10^{-4} & 3,8 \\ \text { Lungernsee } & 24.6 .45 & 13,8 \cdot 10^{-4} & 3,7\end{array}$

Durch vorwiegend Oscillatoria-armes Plankton getrübte Seen

Vierwaldstättersee (Alpnachersee)

Vierwaldstättersee (Luzerner Becken)

Lago di Poschiavo

St.-Moritzer-See

Partnunersee (Prättigau)

Sihlsee

Sihlsee (Staumauer) ${ }^{1}$ )

Sihlsee (Staumauer)

Sihlsee (Staumauer)

Sihlsee $\left.{ }^{1}\right)$

Sihlsee

Sihlsee

Sihlsee

Sihlsee

Sihlsee

Sihlsee

Sihlsee

Sihlsee

Sihlsee

Sihlsee

Zürcher Obersee ${ }^{1}$ )

Zürcher Obersee

Zürcher Obersee

Zürcher Obersee

Zürcher Obersee

Bodensee

Bodensee-Untersee ${ }^{\boldsymbol{l}}$ )

Bodensee-Untersee

Bodensee-Untersee

$\begin{array}{rrr}25.8 .46 & 13,5 \cdot 10^{-4} & 3,0 \\ 25.8 .46 & 8,2 \cdot 10^{-4} & 5,4 \\ 22.9 .46 & 24,8 \cdot 10^{-4} & 2,8 \\ 23.9 .46 & 13,4 \cdot 10^{-4} & 5,7 \\ 9.8 .46 & 6,6 \cdot 10^{-4} & >10 \\ 25.8 .46 & 7,4 \cdot 10^{-4} & 4,5 \\ 23.11 .46 & 10,8 \cdot 10^{-4} & 6,5 \\ 7.5 .46 & 12,4 \cdot 10^{-4} & 3,1 \\ 3.9 .49 & 7,6 \cdot 10^{-4} & 2,9 \\ 3.12 .49 & 18,9 \cdot 10^{-4} & 2,7 \\ 14.1 .50 & 8,3 \cdot 10^{-4} & 2,9 \\ 25.2 .50 & 11,3 \cdot 10^{-4} & 2,5 \\ 2.4 .50 & 19,3 \cdot 10^{-4} & 1,4 \\ 18.6 .50 & 12,1 \cdot 10^{-4} & 1,8 \\ 7.10 .50 & 7,2 \cdot 10^{-4} & 4,8 \\ 20.1 .51 & 10,5 \cdot 10^{-4} & 3,0 \\ 2.3 .51 & 9,3 \cdot 10^{-4} & 3,6 \\ 26.5 .51 & 20,7 \cdot 10^{-4} & 2,4 \\ 11.8 .51 & 7,6 \cdot 10^{-4} & 5,5 \\ 2.2 .52 & 13,5 \cdot 10^{-4} & 2,8 \\ 21.5 .44 & 12,5 \cdot 10^{-4} & 4,6 \\ 16.7 .44 & 26,5 \cdot 10^{-4} & 2,5 \\ 15.10 .44 & 14,8 \cdot 10^{-4} & 5,6 \\ 10.12 .44 & 30,8 \cdot 10^{-4} & 3,2 \\ 17.2 .45 & 11,0 \cdot 10^{-4} & 4,6 \\ 31.9 .46 & 27,0 \cdot 10^{-4} & 3,8 \\ 1.5 .44 & 12,9 \cdot 10^{-4} & 4,4 \\ 4.6 .44 & 27,5 \cdot 10^{-4} & 2,3 \\ 9.7 .44 & 18,8 \cdot 10^{-4} & 3,4\end{array}$

1) $T_{a b s}=$ Mittelwert aus den Stufenproben von 0-5 m Tiefe 
Tabelle 3 (Fortsetzung)

\begin{tabular}{lrrr}
\hline Gewässer & Datum & \multicolumn{1}{c}{$T_{a b s}$} & \multicolumn{1}{c}{$\begin{array}{l}\text { Trans- } \\
\text { parenz } \\
\text { in m }\end{array}$} \\
\hline Bodensee-Untersee & & & \\
Bodensee-Untersee & 10.8 .44 & $19,3 \cdot 10^{-4}$ & 3,4 \\
Bodensee-Untersee & 8.10 .44 & $11,0 \cdot 10^{-4}$ & 5,1 \\
Lago Ritom Profil I & 18.9 .46 & $6,8 \cdot 10^{-4}$ & 7,0 \\
Lago Ritom Profil II & 18.9 .46 & $8,4 \cdot 10^{-4}$ & 11,6 \\
Lago Ritom Profil III & 18.9 .46 & $6,9 \cdot 10^{-4}$ & 10,9 \\
\hline
\end{tabular}

Durch vorwiegend Oscillatoria rubescens getrübte Seen

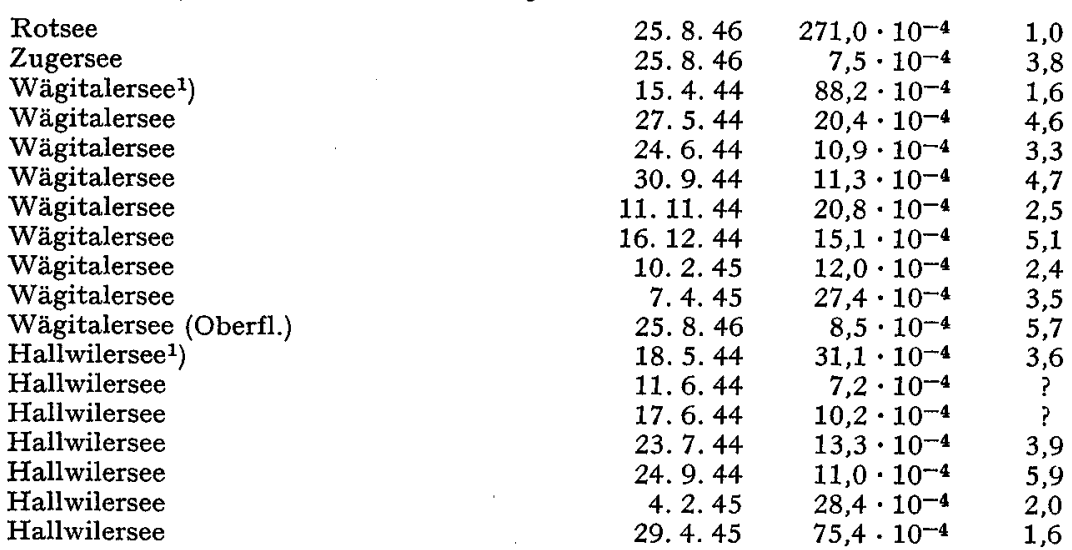

1) $T_{a b s}=$ Mittelwert aus den Stufenproben von 0-5 m Tiefe

sucht wurden und deren Wasser vornehmlich durch eine Planktonproduktion getrübt wird, die keine Wasserblüten bildet und in der insbesondere die Burgunderblutalge fehlt oder (Zürcher Obersee) nur zu geringer Entfaltung gelangt. Die entspechenden Zahlenwerte finden sich in Tab. 3 . In allen drei Fällen handelt es sich um durchschnittlich mittelgetruibte Seen, deren mittlere Trübungswerte zwischen weniger als Io und etwa 30 liegen. Die Korrelationskurven zeigen einen ähnlichen Verlauf wie in Abb. I, insbesondere diejenigen des Sihlsees und des Oscillatoria-freien Untersees. Indessen streuen die Werte der Trübung und Transparenz in ziemlich weitem Masse, was darauf zurückzuführen ist, dass sie aus allen Jahreszeiten stammen, wodurch unterschiedliche und z. T. unkontrollierbare Faktoren mit ins Spiel traten (biogene Entkalkung, Ausflockungen von Eisenocker usw.). 
Auch die Kurven für den Wägitaler Stausee und den Hallwilersee (beides ausgesprochene Oscillatoriaseen) zeigen - wiederum bei weiten Streuungen - gemäss Abb. 3 und Tab. 3 einen Verlauf, der demjenigen der beiden vorgenannten Abbildungen weitgehend entspricht.

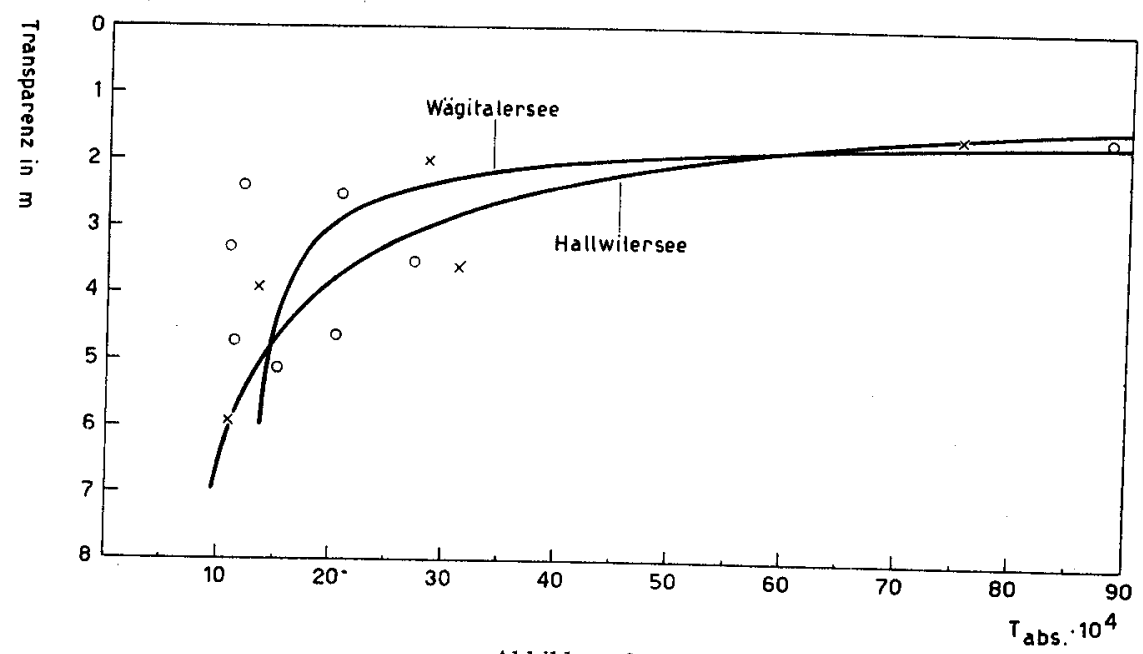

Abbildung 3

Zusammenhang zwischen Transparenz und Trübung bei zwei Seen während längerer Untersuchungsdauer.

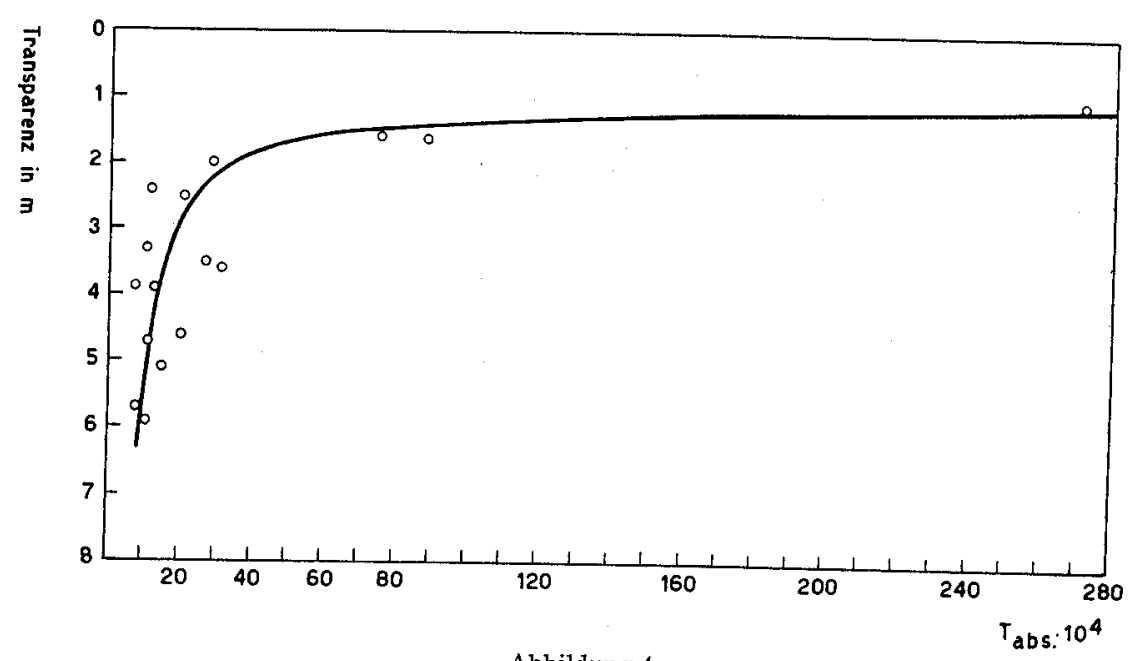

Abbildung 4

Zusammenhang zwischen Transparenz und Trübung bei Oscillatoriaseen. 
Schliesslich gibt Abb. 4 die Abhängigkeit von Trübung und Transparenz für ausgesprochene Oscillatoriaseen wieder. Sie bestätigt in eindrücklicher Weise die Resultate der Korrelation Trübung/Transparenz in den vorgenannten Beispielen.

\section{Die natürliche Klärung des Wassers in verschiedenen Gewässersystemen}

In vielen Schweizer Seen beruht die Wassertrübung auf einer mehr oder weniger starken Entfaltung des pflanzlichen und tierischen Planktons. Aber noch grösser ist die Zahl der stehenden Gewässer, die durch suspendierte, mehr oder weniger fein pulverisierte Gesteinspartikeln getrübt sind. In diesen erreichen die Trübungswerte oft ein Vielfaches der ersteren.

Fliessgewässer von der Art der schweizerischen Flüsse entwickeln kein nennenswertes Plankton. Was sie an Kleinorganismen in ihrem Wasser mitführen, entstammt Seen, Teichen, Sumpfgebieten und Mooren, deren Abflüsse sich mit ihnen vereinigen. Nur die allergrössten unter den europäischen Strömen, wie die Wolga, vermögen auf ihrem Laufe ein Eigenplankton zur Entfaltung zu bringen. In unsern im Hochgebirge und im Voralpengebiet entspringenden Bächen und Flüssen beruht demgemäss die Wassertrübung in allererster Linie auf ihrer Fracht an anorganischen Trübungsstoffen, insbesondere den genannten feinen und feinsten Gesteinspartikelchen.

Wenn indessen die Abflüsse unserer planktonreichen (eutrophen) Mittellandseen trübe und mit einer charakteristischen Eigenfarbe dem Beschauer auffallen, so liegen zumeist Vegetationsfärbungen durch Planktonalgen vor (Limmat unterhalb von Zürich, Hallwiler Aa, Aare beim Ausfluss aus dem Murtensee usw.).

Im folgenden werden die Trübungsverhältnisse einer Reihe von Flusssystemen anhand übersichtlicher graphischer Darstellungen betrachtet und diskutiert.

I. Die Aare vom Oberaargletscher bis zum Bielersee (Abb. 5 und Tab. 4).

In ihrem Quellgebiet weist die Aare die höchsten von uns im Gebiete der Schweiz gemessenen Trübungswerte auf. So wurde im Abfluss des Unteraargletschers ein Wert von I048 festgestellt. In Abb. 5, in der die Ergebnisse unserer Trübungsmessungen graphisch dargestellt sind, wurde dieser hohe Wert aus darstellerischen Gründen nicht eingetragen. 
Hydrol.

Etwas weniger trübe ist der Abfluss des Oberaargletschers; so wurde im Oberaarbach ein Wert von 463 gemessen. Das Wasser des Gelmersees, das von der rechten Seite her in die junge Aare gelangt, ist rund zehnmal klarer und zeigte anlässlich unserer Aufnahme einen Wert von 36,4. Trotzdem die Aare von beiden Seiten her Wildbäche in sich aufnimmt, klärt sich auf ihrem rund $35 \mathrm{~km}$ langen Lauf bis Brienz das Wasser in erheb-

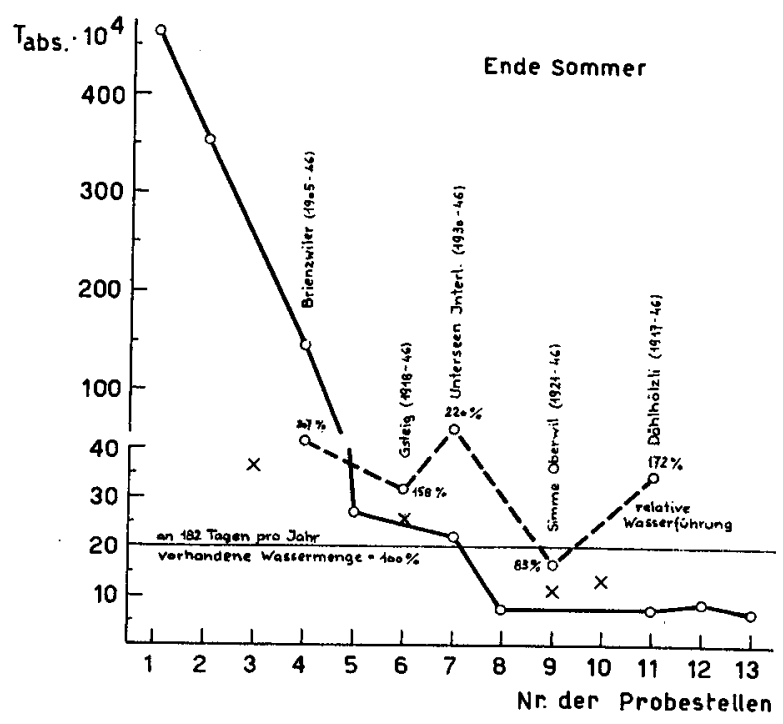

Abbildung 5

Der Verlauf der Trübung der Aare vom Oberaargletscher bis zum Bielersee.

Ausgezogene Kurve: Trübung; gestrichelte Kurve: relative Wasserführung.

lichem Masse, was in einem Trübungswert von I47 (vor der Einmündung in den Brienzersee) zum Ausdruck kommt.

Im Brienzersee selbst erfolgt zunächst eine Ausbreitung (Verdünnung) des getrübten Aarewassers und eine weitgehende Sedimentation der mitgeführten Schwebestoffe. Aber noch ist die mineralische Trübung so hoch, dass die Sichttiefen I m kaum übersteigen und der See in milchighellgrüner Farbe erscheint.

Im Thunersee setzt sich die Sedimentation der Schwebestoffe fort. Seine Trübung zeigte oberhalb von Thun den Wert 7,4; seine Transparenz betrug $5,5 \mathrm{~m}$, und sein Wasser erschien zur Zeit der Probenahme in klarblauer Farbe. Er gehört damit bereits in die Kategorie der Klarseen. Simme 
Tabelle 4

Trübungswerte im System der Aare

$\mathrm{Nr}$

Datum

Trübung in absoluten Einheiten ( $\left.T_{a b s}\right)$

1 Oberaarbach

2 Grimselsee

3 Gelmersee

4 Aare bei Brienz

5 Brienzersee

6 Lütschine bei Bönigen

7 Aareeinfluss Thunersee

8 Thunersee ob Thun

9 Simme ob Stauung (6 $\mathrm{km}$ von Thunersee)

10 Kander vor Zusammenfluss mit der Simme

11 Aare bei Bern

12 Aare bei Hagneck

13 Bielersee bei Twann

$\begin{array}{lr}13.8 .46 & 463 \cdot 10^{-4} \\ 13.8 .46 & 354 \cdot 10^{-4} \\ 28.8 .46 & 36,4 \cdot 10^{-4} \\ 24.8 .46 & 147,0 \cdot 10^{-4} \\ 24.8 .46 & 27,4 \cdot 10^{-4} \\ 24.8 .46 & 25,8 \cdot 10^{-4} \\ 24.8 .46 & 22,0 \cdot 10^{-4} \\ 24.8 .46 & 7,4 \cdot 10^{-4} \\ 24.8 .46 & 11,2 \cdot 10^{-4} \\ 24.8 .46 & 13,3 \cdot 10^{-4} \\ 24.8 .46 & 7,5 \cdot 10^{-4} \\ 25.8 .46 & 8,8 \cdot 10^{-4} \\ 31.8 .46 & 6,8 \cdot 10^{-4}\end{array}$

und Kander weisen etwas höhere Trübungswerte auf, ohne indes die Klarheit des Aarewassers in wesentlichem Masse zu beeinflussen. Bis in den Bielersee hält es sich mit geringen Schwankungen auf Trübungswerten, die unter to liegen.

\section{System Reuss-Vierwaldstättersee \\ (Abb. 6 und Tab. 5)}

Ähnlich wie sich die junge Aare in den von ihr durchflossenen Seen klärt, vollzieht sich die Klärung des Wassers der Reuss beim Eintritt und beim Durchgang durch den Vierwaldstättersee. Auf der Höhe von Altdorf, also kurz vor ihrer Einmündung in den Urnersee, zeigt die

Tabelle 5

Trübung des Reusswassers auf dem Weg durch den Vierwaldstättersee

Nr.

Trübung in absoluten Einheiten $\left(T_{a b s}\right)$ 


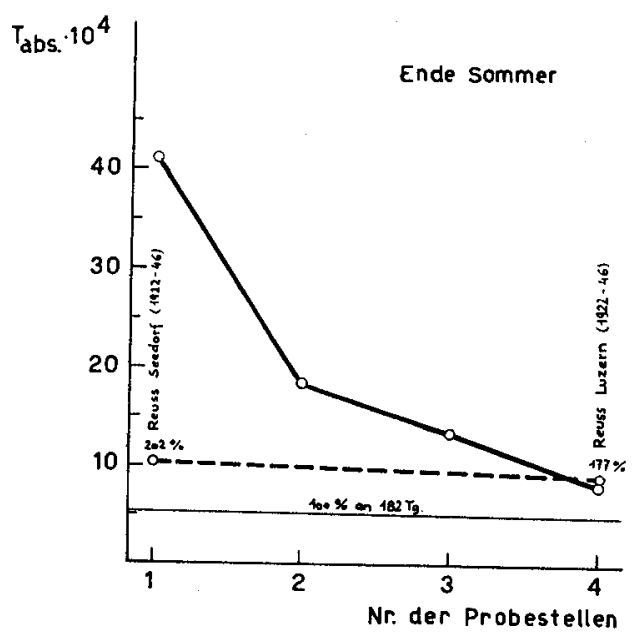

Abbildung 6

Der Verlauf der Trübung des Reusswassers auf dem Weg durch den Vierwaldstättersee. Ausgezogene Kurve: Trübung; gestrichelte Kurve: relative Wasserführung.

Reuss einen Trübungswert von 4I,2. Unweit unterhalb der Mündung sinkt der Wert im See auf 18,5 , vor Flüelen auf 13,5 und im unteren Seeteil in der Bucht von Luzern, wo die Reuss den Vierwaldstättersee wieder verlässt, auf 8,2. In dieser Reihe von Trübungswerten findet die fortschreitende Sedimentation der Trübungsstoffe ihren Ausdruck. Ist der Urnersee noch in die Kategorie der mitteltrüben Gewässer einzureihen, so kann der Luzerner Seeteil bereits als Klarsee bezeichnet werden.

\section{System Broye--Murtensee, Lac de Neuchâtel-Bielersee}

(Abb.7 und Tab.6)

Im Murtensee sedimentieren sich die Trübungsstoffe der Broye so weit, dass der Trübungswert von 16,6 (Broye) auf Io,3 (Murtensee) absinkt. Im Broyekanal, im Neuenburgersee und im Zihlkanal erfolgt eine weitere Klärung, und im Bielersee stellten wir noch eine Trübung von 6,8 fest. Gewiss lägen die Verhältnisse im Herbst und Frühjahr, insbesondere im Murtensee, wesentlich anders. In diesen Jahreszeiten gelangt nämlich unter der Wirkung der durch den Temperaturgang des Wassers bedingten Zirkulationsströmungen die Planktonvegetation, insbesondere die grosse Masse der Burgunderblutalgen (Oscillatoria rubescens) aus 
der Tiefe von 8-I2 $\mathrm{m}$ an die Seeoberfläche, wodurch der Grad der Trübung in sehr bedeutendem Ausmasse heraufgesetzt, die Durchsichtigkeit in entsprechender Weise herabgesetzt wird. Um diese Verhältnisse in einem System von fliessenden und stehenden Gewässern im jahreszeitlichen Gang festzustellen, müssten deshalb über das ganze Jahr verteilte Erhebungen durchgeführt werden.

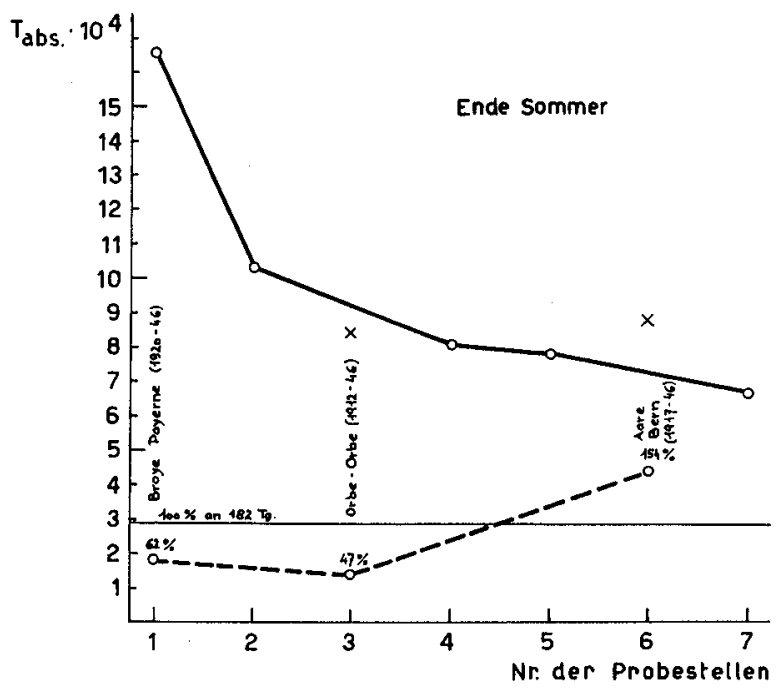

Abbildung 7

Verlauf der Wassertrübung im Gewässersystem Broye-Murtensee-Lac de Neuchâtel-Bielersee.

Ausgezogene Kurve: Trübung; gestrichelte Kurve: relative Wasserführung.

Tabelle 6

Die $W$ assertrübung im System Broye-Furarandseen

\begin{tabular}{lcc}
\hline Nr. & Datum & $\begin{array}{l}\text { Trübung in ab- } \\
\text { soluten Einheiten } \\
\left(T_{a b s}\right)\end{array}$ \\
\hline 1 Broye bei Salavaux & & \\
2 Murtensee bei Murten & 25.8 .46 & $16,6 \cdot 10^{-4}$ \\
3 Yverdon, Thielle & 25.8 .46 & $10,3 \cdot 10^{-4}$ \\
4 Neuenburg, Hafen & 25.8 .46 & $8,4 \cdot 10^{-4}$ \\
5 Zihlkanal bei Landeron & 25.8 .46 & $8,1 \cdot 10^{-4}$ \\
6 Aare bei Hagneck & 25.8 .46 & $7,8 \cdot 10^{-4}$ \\
7 Bielersee bei Twann & 25.8 .46 & $8,8 \cdot 10^{-4}$ \\
& 31.8 .46 & $6,8 \cdot 10^{-4}$ \\
\hline
\end{tabular}


4. System Lungernsee-Sarnersee-Vierwaldstättersee

(Abb. 8 und Tab. 7)

Obwohl am Aufnahmetag der Hauptzufluss zum Lungernsee verhältnismässig klares Wasser führte $(8,5)$, erschien der See selbst bei einem Wert von $\mathrm{I}_{4}, \mathrm{O}$ als ziemlich trübe. Ob dieser Zustand auf eine intensive Planktonproduktion zurückzuführen ist, oder aber, ob der Regen, der drei Tage zuvor gefallen war, diese Trübung verursachte (Feingeschiebeführung des Zuflusses), lässt sich kaum ermitteln, da uns die diesbezüglichen Unterlagen fehlen. Indes zeigt sich bis zum Sarnersee doch (ähn-

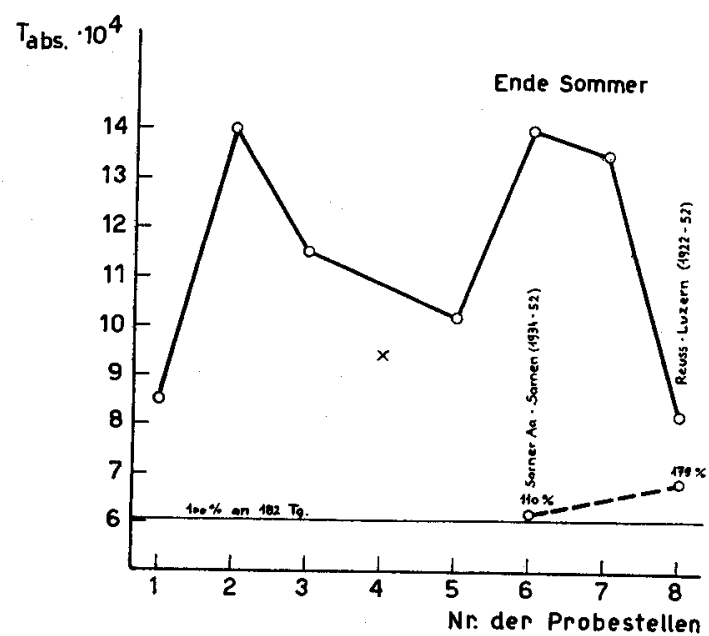

Abbildung 8

Verlauf der Wassertrübung im Gewässersystem Lungernsee-Sarnersee-Vierwaldstättersee. Ausgezogene Kurve: Trübung; gestrichelte Kurve: relative Wasserführung.

Tabelle 7

Trübung im Gemässersystem Lungernsee-Sarnersee-Viermaldstättersee

\begin{tabular}{lrr}
\hline Nr. & Datum & $\begin{array}{l}\text { Trübung in ab- } \\
\text { soluten Einheiten } \\
\left(T_{a b s}\right)\end{array}$ \\
\hline 1 Lungernsee, Hauptzufluss & & $8,5 \cdot 10^{-4}$ \\
2 Lungernsee, Seemitte & 24.8 .46 & $14,0 \cdot 10^{-4}$ \\
3 Aaeinfluss Sarnersee & 24.8 .46 & $11,5 \cdot 10^{-4}$ \\
4 Sarnerseezufluss & 24.8 .46 & $9,4 \cdot 10^{-4}$ \\
5 Sarnersee, Seemitte & 24.8 .46 & $10,2 \cdot 10^{-4}$ \\
7 Alpnachersee, Hauptzufluss & 24.8 .46 & $14,0 \cdot 10^{-4}$ \\
8 Luzerner Bucht & 24.8 .46 & $13,5 \cdot 10^{-4}$ \\
\end{tabular}


lich wie in den oben diskutierten Beispielen) eine unbedeutende Klärung des Wassers bis auf den Wert 10,2. Der Alpnachersee aber zeigt wiederum eine relativ hohe Trübung, die sich seeabwärts vermindert bis nach Luzern, wo ein Wert von 8,2 festgestellt wurde.

\section{System Ägerisee-Zugersee-Lorze \\ (Abb. 9 und Tab. 8)}

Die Verhältnisse dürften in diesem Gewässersystem ähnlich liegen wie in demjenigen des Lungernsee-Sarnersee-Alpnachersees. Beide untersuchten Zuflüsse, deren Wasser in den Ägerisee einmünden, sind klarer als der See

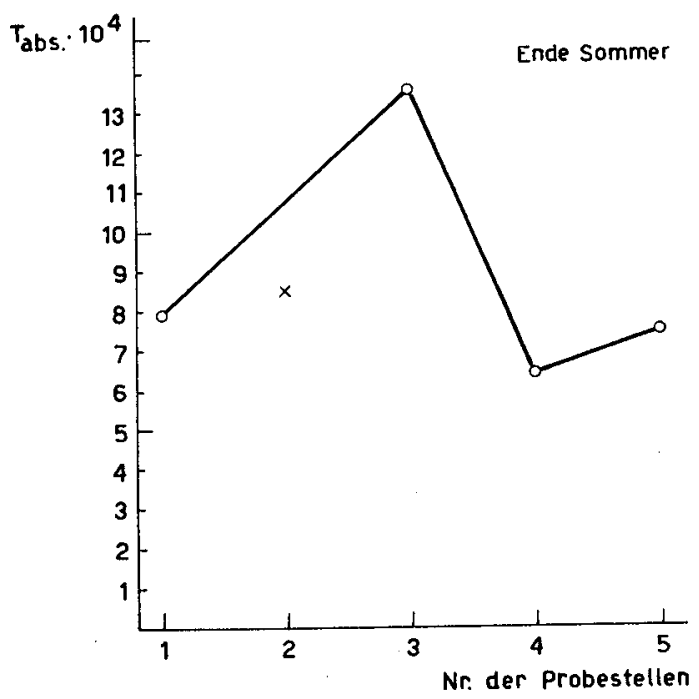

Abbildung 9

Der Verlauf der Wassertrübung im System Ägerisee-Zugersee-Lorze.

Tabelle 8

Wassertrübung vom Ägerisee bis zur Lorze

\begin{tabular}{lrr}
\hline Nr. & Datum & \multicolumn{1}{c}{$\begin{array}{c}\text { Trübung in ab- } \\
\text { soluten Einheiten } \\
\left(T_{a b s}\right)\end{array}$} \\
\hline 1 Ägerisee, Hauptzufluss Hüribach & 25.8 .46 & $7,9 \cdot 10^{-4}$ \\
2 Ägerisee, Zufluss Dorfbach (Oberägeri) & 25.8 .46 & $8,5 \cdot 10^{-4}$ \\
3 Ägerisee, Seemitte & 25.8 .46 & $13,6 \cdot 10^{-4}$ \\
4 Zugersee, Lorzemündung & 25.8 .46 & $6,4 \cdot 10^{-4}$ \\
5 Zugersee, Seemitte & 25.8 .46 & $\mathbf{7 , 5 \cdot 1 0 ^ { - 4 }}$ \\
\hline
\end{tabular}


selbst. Die Ursache dürfte die sommerliche Planktonentwicklung sein. Es ist bekannt, dass auf einer verhältnismässig kurzen Fließstrecke die Planktonorganismen, die der Fluss aus dem See mitführt, abgetötet und rasch eliminiert werden. Daraus erklärt sich auch die geringe Trübung des Zugersees bei der Lorzemündung. Die Trübung stieg bis zur Seemitte von 6,4 auf 7,6 an, was wiederum auf die Planktonentwicklung zurückzuführen sein dürfte.

6. System des Inn und der Oberengadiner Seen

(Abb. Io und Tab. 9)

Der Inn, der am idyllisch gelegenen Lunghinsee auf der linken Talseite des Oberengadins entspringt, führt ein sehr klares Wasser. Silser- und Silvaplanersee, die von ihm durchflossen werden, nehmen von beiden Seiten her die Wasser von Wildbächen auf, die zur Zeit der Schneeschmelze und bei Platzregen den Seen bedeutende Mengen von Schutt und Feingeschiebe zuführen; deshalb sind die Oberengadiner Seen meist leicht getrübt, weisen geringe Sichttiefen von $1,2-3 \mathrm{~m}$ auf und erscheinen oft in milchig heller, grünlichblauer Farbe.

Das Wasser des Inn wird deshalb in diesen Seen nicht geklärt, sondern mit Schwebestoffen in mehr oder weniger hohem Masse belastet. Hemmend auf den Vorgang der Sedimentierung der suspendierten Stoffe dürfte sich überdies der bekannte, periodisch auftretende Malojawind auswirken, der die Wasser der Seen und damit auch die suspendierten Stoffe immer wieder in Bewegung bringt.

Dazu kommt weiterhin die Trübung des Wassers durch die Entwicklung des Seeplanktons, das aber angesichts der hohen Lage der Oberengadiner Seen nicht allzu bedeutend ist. Silser- und Silvaplanersee (in Abb. Io Messpunkte 2 und 5) zeigen denselben Trübungswert von rund 18 Einheiten. Obschon die gemessenen Werte von drei $\mathrm{Zu}-$ flüssen zum Silvaplanersee $z$. T. bedeutend tiefer liegen, nimmt die Trübung bis zum Abfluss zu, was möglicherweise auf die Planktonentwicklung zurückzuführen ist. In den Campfèr- und St.-Moritzer-See münden nur unbedeutende Wildbäche, so dass sich das Wasser wiederum in erheblichem Masse zu klären vermag. Aber stets zeigt der Campfèrsee eine milchigblaue Wasserfarbe, während der St.-Moritzer-See mit einer eher blaugrünen Farbe erscheint und Transparenzen bis zu $6 \mathrm{~m}$ zeigt. Der grüne Stich im letztgenannten See dürfte auf Planktonentwicklungen zurückzuführen sein. 


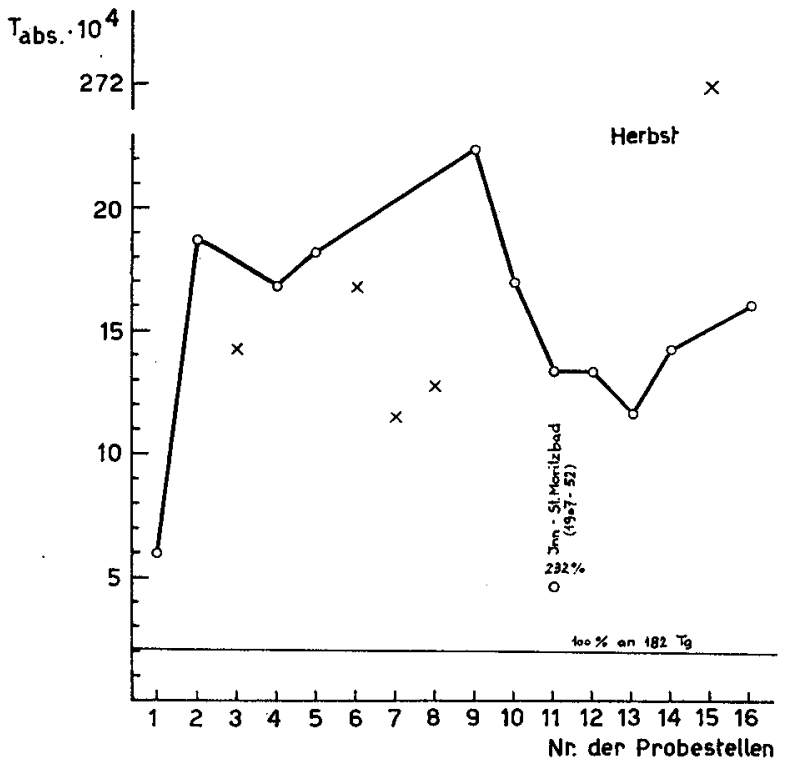

Abbildung 10

Der Verlauf der Wassertrübung im Gewässersystem Oberengadiner Seen-Inn.

Tabelle 9

Die W assertrübung im System der Oberengadiner Seen

Nr.

1 Inn (Maloja)

2 Silsersee, Seemitte

3 Ova da Fedoz

4 Inn unterhalb von Sils Baselgia

5 Silvaplanersee

6 Ova da Fex

7 Ova del Vallun (Strassenbrücke)

8 Zufluss vom Vadret

9 Abfluss des Silvaplanersees

10 Campfèrsee nahe dem Abfluss

11 Inn (St. Moritz-Bad; Post)

12 St.-Moritzer-See, Seemitte

13 Inn oberhalb Innschlucht

14 Inn (zwischen Celerina und Samedan)

15 Il Flaz vor Mündung in Inn

16 Inn (Samedan)
Datum

Trübung in absoluten Einheiten $\left(T_{a b s}\right)$
23. 9.46

23. 9.46

23. 9.46

23. 9.46

23. 9.46

23. 9.46

23. 9.46

23. 9.46

23. 9.46

23. 9.46

23. 9.46

23. 9.46

23. 9.46

23. 9.46

23. 9.46

23. 9.46
$6,0 \cdot 10^{-4}$

$18,7 \cdot 10^{-4}$ $14,3 \cdot 10^{-4}$ $16,8 \cdot 10^{-4}$

$18,2 \cdot 10^{-4}$

$16,8 \cdot 10^{-4}$

$11,5 \cdot 10^{-4}$

$12,8 \cdot 10^{-4}$

$22,4 \cdot 10^{-4}$

$17,0 \cdot 10^{-4}$

$13,4 \cdot 10^{-4}$

$13,4 \cdot 10^{-4}$

$11,7 \cdot 10^{-4}$

$14,3 \cdot 10^{-4}$

$272,0 \cdot 10^{-4}$

$16,1 \cdot 10^{-4}$ 
Verhältnismässig klar (II,7) tritt der Inn in seine Schlucht ein. Aber nun nimmt er im Il Flaz die durch einen hohen Gehalt an Feingeschiebe getrübten Wasser des Berninabaches auf, wodurch sein Trübungswert auf der Höhe von Samedan wiederum auf 16,I ansteigt.

7. Der Ova del Bernina und sein Einzugsgebiet (Abb. II und Tab. ro)

Der Berninabach trägt die ausgesprochenen Züge eines Hochgebirgsgewässers. Seine Quellseen Lago Nero und Lej Pitschen, auf einer Höhe von $2300 \mathrm{~m}$ ü. M. und auf der Wasserscheide zwischen dem Schwarzen Meer und der Adria gelegen, führen ein Wasser von höchster Klarheit. Auch die aus noch höher gelegenen Schutthalden entspringenden Bächlein sind klar. Bis zu den Berninafällen, wo die Wasserprobe im Sturztrichter gefasst wurde, liegen die Trübungswerte ausschliesslich unter 9. Im Bach aus dem Val Minor wurde ein Wert von nur 3,7 festgestellt.

Aber aus dem Tal des Morteratschgletschers bringt nun der Vadret da Morteratsch ein sehr stark getrübtes Wasser (Wert 582), ebenso der

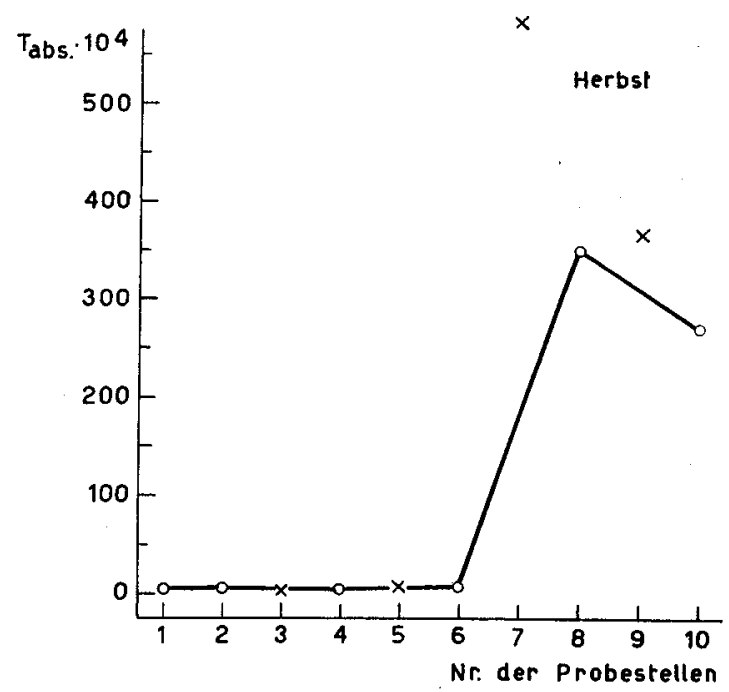

Abbildung 11

Verlauf der Trübung im Ova del Bernina und seinen Zuflüssen. 
Trübungsperte im Opa del Bernina und seinen Zuflüssen

\begin{tabular}{lrr}
\hline Nr. & Datum & \multicolumn{1}{l}{$\begin{array}{l}\text { Trübung in ab- } \\
\text { soluten Einheiten } \\
\left(T_{a b s}\right)\end{array}$} \\
\hline 1 Lago Nero & 22.9 .46 & $5,5 \cdot 10^{-4}$ \\
2 Abfluss des Lej Pitschen & 22.9 .46 & $6,8 \cdot 10^{-4}$ \\
3 Bach aus Val Minor & 22.9 .46 & $3,7 \cdot 10^{-4}$ \\
4 Ova del Bernina oberhalb Zufluss aus Val del Fain & 22.9 .46 & $5,6 \cdot 10^{-4}$ \\
5 Bach aus Val del Fain & 22.9 .46 & $8,6 \cdot 10^{-4}$ \\
6 Berninafälle (aus Sturztrichter) & 22.9 .46 & $8,6 \cdot 10^{-4}$ \\
7 Zufluss vom Vadret da Morteratsch & 22.9 .46 & $582 \cdot 10^{-4}$ \\
8 Ova del Bernina (Pontresina) & 22.9 .46 & $351 \cdot 10^{-4}$ \\
9 Ova da Roseg (Abfluss des Roseggletschers) & 22.9 .46 & $367 \cdot 10^{-4}$ \\
10 Il Flaz (Unterlauf der Ova del Bernina) vor Ein- & 22.9 .46 & $272 \cdot 10^{-4}$ \\
\hline mündung in den Inn & & \\
\hline
\end{tabular}

Ova del Bernina bei Pontresina (35I), der Abfluss des Roseggletschers (367), so dass Il Flaz (Unterlauf des Ova del Bernina) vor der Einmündung in den Inn noch den Trübungswert von 272 aufweist.

\section{Ritomsee und Lago di Cadagno}

Die Pioraseen, nämlich Ritomsee, Lago di Cadagno, Lago Tom, Lago di Taneda, aber auch die noch höher gelegenen Seen, wie Lago Scuro usw., und ihre $\mathrm{Zu}$ - und Abflüsse geben dem Beschauer den Eindruck sehr klarer Gewässer. In der Tat ist die Oberfläche des Ritomsees mit einem Trübungswert von 6,2 ausgewiesen. Aber schon in der Tiefe von I $\mathrm{m}$ steigt der Trübungswert an, um allerdings in ro- $\mathrm{I} 5 \mathrm{~m}$ und in $25 \mathrm{~m}$ unter der Wasseroberfläche auf verhältnismässig tiefe Werte abzusinken.

Diese eigentümlichen Trübungsverhältnisse sind auf die spezifischen biologischen Gegebenheiten des Ritomsees zurückzuführen. In ihm kommen rotgefärbte Schwefelbakterien in so grossen Mengen zur Entfaltung, dass das Wasser nicht nur getrübt, sondern auch auffallend rot gefärbt wird (1946!). Die Tiefenverteilung dieser Bakterien ist unterschiedlich je nach ihrer Art.

So finden wir die sulfatreduzierenden Formen wie Microspira (Vibrio) desulfuricans in den sauerstoff freien Tiefenschichten. Diese Bakterien liefern als Endprodukt der Sulfat(Gips)reduktionen Schwefelwasserstoff, während andere Bakterienarten, wie Chromatium Okeni, Beggiatoa 
alba, Lamprocystis usw., den in die durchlüfteten höheren Wasserschichten aufsteigenden Schwefelwasserstoff oxydieren.

Zeitweise ist die Entfaltung solcher Bakterien in so hohem Masse auf bestimmte Tiefenschichten lokalisiert, dass man schon von «Bakterienbrettern» gesprochen hat. Mit den sich vertikal verschiebenden Sauerstoffverhältnissen heben und senken sich auch die verschiedenen Bakterienteppiche. Erst die Konvektionsströmungen vermögen diese Schichtung auszugleichen, und dies wiederum nur teilweise, infolge des höheren spezifischen Gewichtes der gipsreichen Tiefenschichten des Wassers.

Der Ritomsee und der etwas höher gelegene Lago di Cadagno nehmen durch diese Verhältnisse unter allen mitteleuropäischen Seen eine Sonderstellung ein. Wir sahen darin einen besonderen Grund, diese Gewässer in unsere Untersuchung einzubeziehen.

Die durch die Entfaltung von Schwefelbakterien bedingten höchsten Trübungswerte liegen im Ritomsee in einer Tiefe von 36,5 m (I8./19. August 1946) bzw. bei 28,o m (17. August 1947). Im Lago di Cadagno (I7. August 1947) ist zwischen klareren Wasserschichten eine trübe Schicht eingeschoben, die von 7,5 bis zu ro $\mathrm{m}$ Tiefe reicht (Tab. II und I2).

Tabelle 11

Tabelle 12

Die durch Schmefelbakterien bedingte

Trübung im Ritomsee

Die durch Schmefelbakterien bedingte Trübung im Lago di Cadagno

\begin{tabular}{|c|c|c|c|c|c|}
\hline \multicolumn{2}{|c|}{$\begin{array}{l}\text { 18./19. Aug. } 1946 \\
\text { Stauhöhe } 48 \mathrm{~m}\end{array}$} & \multicolumn{2}{|c|}{$\begin{array}{l}\text { 17. Aug. } 1947 \\
\text { Stauhöhe } 40 \mathrm{~m}\end{array}$} & \multicolumn{2}{|c|}{ 17. Aug. 1947} \\
\hline Tiefe $\mathrm{m}$ & $T_{a b s}$ & Tiefe $\mathrm{m}$ & $T_{a b s}$ & Tiefe m & $T_{a b s}$ \\
\hline 0 & $5,5 \cdot 10^{-4}$ & 0 & $6,2 \cdot 10^{-4}$ & 0 & $11,4 \cdot 10^{-4}$ \\
\hline 1,0 & $8,1 \cdot 10^{-4}$ & 5,0 & $13,4 \cdot 10^{-4}$ & 2,5 & $7,0 \cdot 10^{-4}$ \\
\hline 2,5 & $10,2 \cdot 10^{-4}$ & 10,0 & $13,4 \cdot 10^{-4}$ & 5,0 & $9,0 \cdot 10^{-4}$ \\
\hline 5,0 & $9,7 \cdot 10^{-4}$ & 15,0 & $10,9 \cdot 10^{-4}$ & $6 \cdot 5$ & $9,0 \cdot 10^{-4}$ \\
\hline 7,5 & $9,3 \cdot 10^{-4}$ & 20,0 & $12,0 \cdot 10^{-4}$ & 7,5 & $14,5 \cdot 10^{-4}$ \\
\hline 10,0 & $8,9 \cdot 10^{-4}$ & 25,0 & $4,9 \cdot 10^{-4}$ & 10,0 & $14,5 \cdot 10^{-4}$ \\
\hline 15,0 & $10,2 \cdot 10^{-4}$ & 27,5 & $7,7 \cdot 10^{-4}$ & 12,5 & $7,0 \cdot 10^{-4}$ \\
\hline 20,0 & $6,4 \cdot 10^{-4}$ & 28,0 & $25,0 \cdot 10^{-4}$ & 15,0 & $10,2 \cdot 10^{-4}$ \\
\hline 25,0 & $8,7 \cdot 10^{-4}$ & 28,5 & $7,7 \cdot 10^{-4}$ & & \\
\hline 30,0 & $9,1 \cdot 10^{-4}$ & 30,0 & $13,1 \cdot 10^{-4}$ & & \\
\hline 36,5 & $21,7 \cdot 10^{-4}$ & 32,5 & $11,6 \cdot 10^{-4}$ & & \\
\hline 40,0 & $15,8 \cdot 10^{-4}$ & 35,0 & $13,4 \cdot 10^{-4}$ & & \\
\hline 48,0 & $11,7 \cdot 10^{-4}$ & 40,0 & $13,4 \cdot 10^{-4}$ & & \\
\hline
\end{tabular}


9. Das Gewässersystem des Rheins

Die Trübungsperbältnisse in $W$ asser des Hinterrbeins somie seiner Zuflüsse wäbrend einer niederscblagsarmen Periode (Abb.12, Tab. 13)

Die Quellen des Hinterrheins liegen in Rheinwaldfirn. Überraschenderweise ist der Abfluss dieses Gletschers mit dem Trübungswert 9,9 im Vergleich zu anderen Gletscherabflüssen verhältnismässig klar, was seinen Grund darin haben mag, dass die Probenahme in der Zeit vom 6. bis 8. Oktober 1946, also am Ende der Schneeschmelze, erfolgte. Verschiedene kleinere Bäche münden von beiden Talseiten her in den Hinterrhein. Sie zeigen im allgemeinen Trübungswerte, die unter 5 liegen. Die Taxierung durch das Auge «sehr klar» findet also durch die exakte Feststellung des Trübungswertes ihre Bestätigung. Das Wasser des Tambobaches freilich ist weniger klar; hier wurde der Wert II,6 festgestellt. Bis zum Dorfe Splügen hat sich im jungen Hinterrhein das Wasser bereits bis auf den Wert 6 geklärt. Auch die unterhalb Splügen

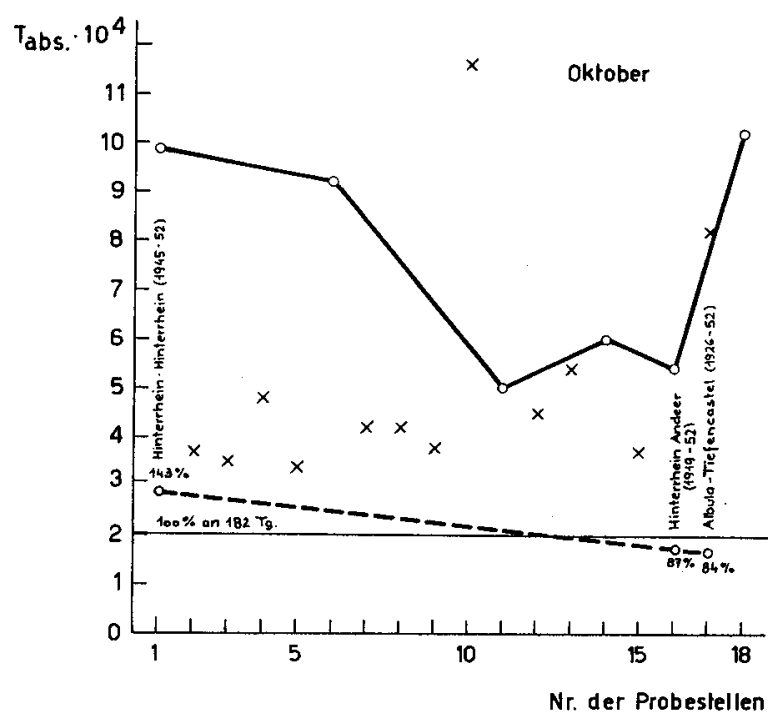

Abbildung 12

Hinterrhein vom Hinterrheingletscher bis Reichenau. Verlauf der Wassertrübung während einer niederschlagsarmen Periode.

Ausgezogene Kurve: Trübung; gestrichelte Kurve: relative Wasserführung. 
Tabelle 13

Hinterrbein vom Hinterrbeingletscber bis Reichenau. Trübung in absoluten Einbeiten $\left(T_{a b s}\right)$ wäbrend niederscblagsarmer Periode

\begin{tabular}{lrr}
\hline Nr. & Datum & \multicolumn{1}{c}{$T_{a b s}$} \\
\hline 1 Hinterrhein, Gletscherabfluss ob Brücke zum Bernardino- & & \\
pass & 6.10 .46 & $9,9 \cdot 10^{-4}$ \\
2 1. Bach von rechts unterhalb obiger Brücke & 6.10 .46 & $3,7 \cdot 10^{-4}$ \\
3 Trosbach, 1. T.1) & 6.10 .46 & $3,5 \cdot 10^{-4}$ \\
4 Räpierbach unterhalb Hinterrhein, 1. T. & 6.10 .46 & $4,8 \cdot 10^{-4}$ \\
5 Capellabach ob Nufenen, r. T. ${ }^{2}$ ) & 6.10 .46 & $3,4 \cdot 10^{-4}$ \\
6 Hinterrhein ob Nufenen & 6.10 .46 & $9,2 \cdot 10^{-4}$ \\
7 Bach von links ob Nufenen & 6.10 .46 & $4,2 \cdot 10^{-4}$ \\
8 Arenebach bei Nufenen, r. T. & 6.10 .46 & $4,2 \cdot 10^{-4}$ \\
9 Letzter Bach von links unter Nufenen & 6.10 .46 & $3,8 \cdot 10^{-4}$ \\
10 Tambobach unter Medels, r. T. & 6.10 .46 & $11,6 \cdot 10^{-4}$ \\
11 Hinterrhein ob Mündung Häusernbach & 6.10 .46 & $5,0 \cdot 10^{-4}$ \\
12 Häusernbach vom Splügenpass, r. T. & 6.10 .46 & $4,5 \cdot 10^{-4}$ \\
13 Sustenbach-Safienbach & 6.10 .46 & $5,4 \cdot 10^{-4}$ \\
14 Hinterrhein 100 m unterhalb Kirche in Splügen & 6.10 .46 & $6,0 \cdot 10^{-4}$ \\
15 Averser Rhein in den Kehren, r. T. & 6.10 .46 & $3,7 \cdot 10^{-4}$ \\
16 Hinterrhein vor Mündung Albula & 8.10 .46 & $5,4 \cdot 10^{-4}$ \\
17 Albula vor Mündung & 8.10 .46 & $8,2 \cdot 10^{-4}$ \\
18 Hinterrhein ob Reichenau & 8.10 .46 & $10,2 \cdot 10^{-4}$ \\
1) T. T. = linke Talseite & & \\
2) r. T. = rechte Talseite & & \\
\hline
\end{tabular}

einmündenden Bäche und Flüsse sind klar, insbesondere der Averser Rhein, der mit einem Trübungswert von nur 3,7 ausgewiesen ist. Oberhalb Reichenau erreicht der Hinterrhein eine Trübung von 10,2.

Weniger klar ist das Wasser des Vorderrheins, der den Glenner mit einer Trübung von I5,6 aufnimmt und selber bis oberhalb Reichenau diesen gleichen Wert beibehält.

Unterhalb des Dorfes Reichenau erfährt der vereinigte Rhein durch die Abwasser einer Fabrik vorübergehend eine Erhöhung des Trübungswertes, der sich indes auf kurzer Fließstrecke wieder vermindert. Aber durch den Zufluss der Landquart wird das Rheinwasser wiederum trüber, und unter der Wirkung weiterer Zuflüsse steigt der Trübungswert bis zur Einmündung in den Bodensee bis auf $9 \mathrm{r}$ an.

Hiezu lässt sich freilich sagen, dass der Untersuchung im Vorderrhein und Schweiz-Vorarlberger Rhein bis zur Mündung in den Bodensee, die in die Tage vom 7./8. Oktober 1946 fiel, eine Periode reichlicher Niederschläge in der Ostschweiz vorangegangen war, wie dies aus Abb. $\mathrm{r}_{3}$ und Tab. I4 hervorgeht, so dass die gewonnenen Werte sich nicht ohne 


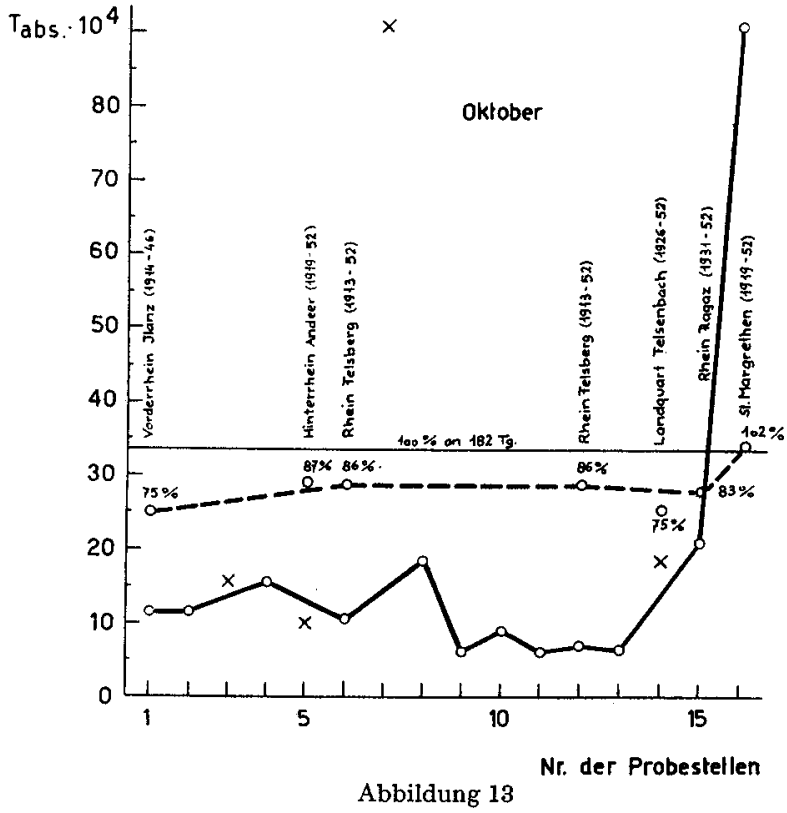

Verlauf der Trübung im Rhein nach einer dreitägigen Periode mit schwachem Niederschlag.

Ausgezogene Kurve: Trübung; gestrichelte Kurve: relative Wasserführung

\section{Tabelle 14}

Rbein. Verlauf der Trübung $\left(T_{a b s}\right)$ nacb drei sebr niederscblagsreicben Tagen der Ostscbweiz

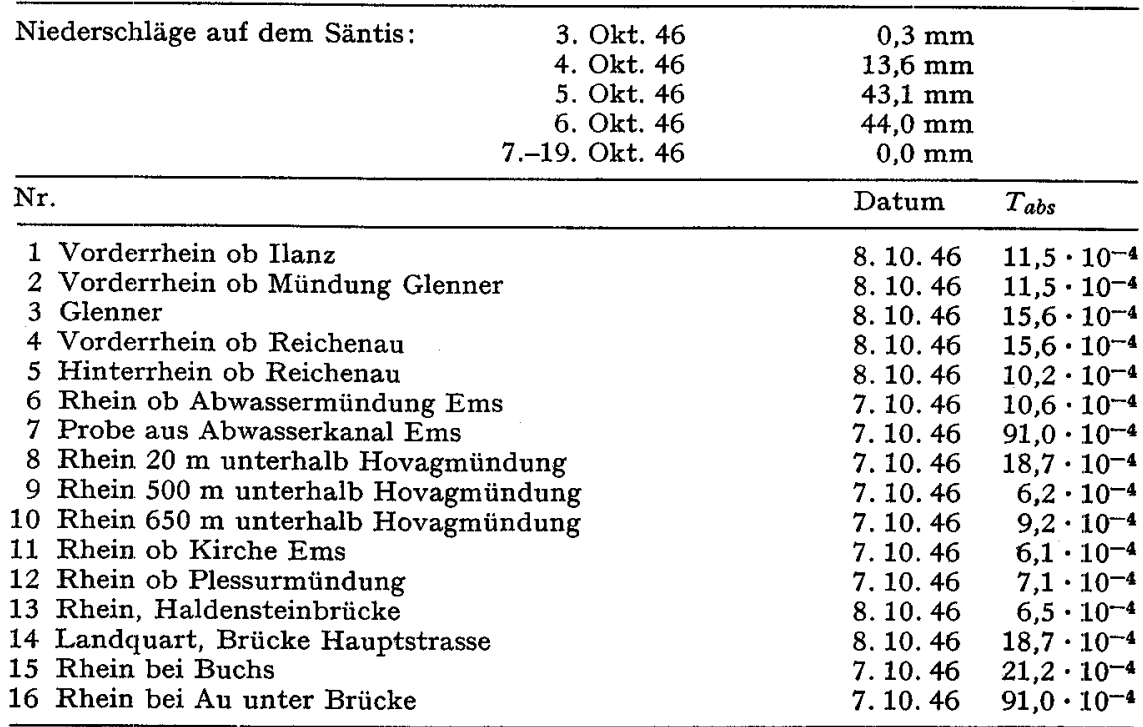




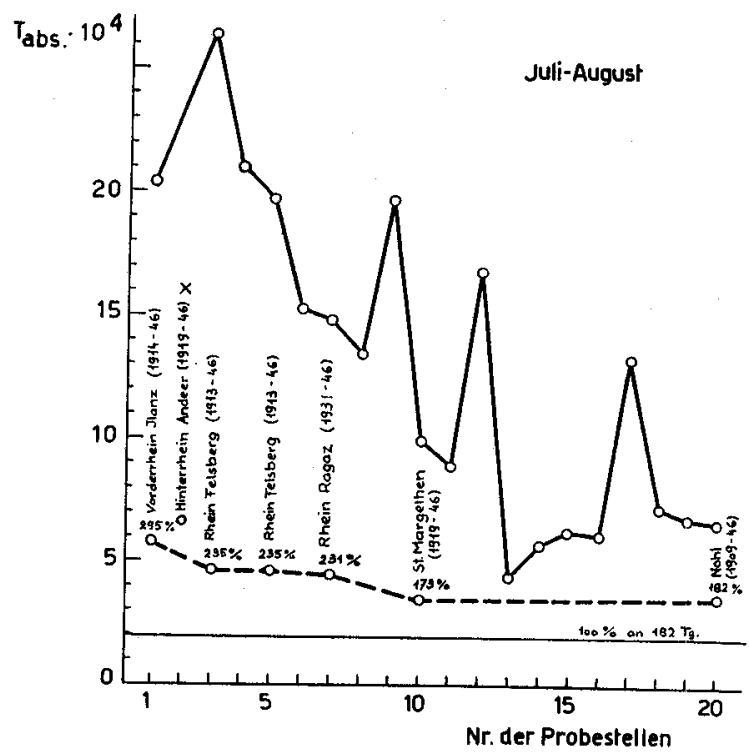

Abbildung 14

Verlauf der Wassertrübung im Gewässersystem des Rheins von Ilanz (Vorderrhein) bis unterhalb Schaffhausen.

Ausgezogene Kurve: Trübung; gestrichelte Kurve: relative Wasserführung

Tabelle 15

Gewässersystem Rbein. Trübung in absoluten Einbeiten $\left(T_{a b s}\right)$

\begin{tabular}{|c|c|c|c|}
\hline $\mathrm{Nr}$. & & Datum & $T_{a b s}$ \\
\hline & Vorderrhein ob Ilanz (ob Abwassereinmündung) & 30.7 .46 & $20,4 \cdot 10^{-4}$ \\
\hline & Hinterrhein, Vereinigung mit Albula. & 30.7 .46 & $16,0 \cdot 10^{-4}$ \\
\hline & Ems, Fabrik (unterhalb Einmündung) & 30.7 .46 & $26,4 \cdot 10^{-4}$ \\
\hline & Ems, Kirche (ob grosser Kanalisation) & 31.7 .46 & $21,0 \cdot 10^{-4}$ \\
\hline & Felsberg (unter Brücke) & 31.7 .46 & $19,7 \cdot 10^{-4}$ \\
\hline & Haldenstein (ob Brücke) & 31.7 .46 & $15,3 \cdot 10^{-4}$ \\
\hline & Ragaz (rechte Seite) & 31.7 .46 & $14,8 \cdot 10^{-4}$ \\
\hline & $\begin{array}{l}\text { Trübbach } \\
\text { Buchs }\end{array}$ & 31.7 .46 & $13,5 \cdot 10^{-4}$ \\
\hline & & 31.7 .46 & $19,7 \cdot 10^{-4}$ \\
\hline 11 & & 4. 8.46 & $9,9 \cdot 10^{-4}$ \\
\hline 12 & $\begin{array}{l}\text { Rorschach } \\
\text { Romanshorn }\end{array}$ & 4. 8.46 & $8,9 \cdot 10^{-4}$ \\
\hline 13 & $\begin{array}{l}\text { Romanshorn } \\
\text { Konstanzer Trichter }\end{array}$ & 4. 8.46 & $16,8 \cdot 10^{-4}$ \\
\hline & $\begin{array}{l}\text { Nonstanzer Irichter } \\
\text { Seerhein, Gottlieben }\end{array}$ & 4. 8.46 & $4,4 \cdot 10^{-4}$ \\
\hline 15 & Ermatingen & 4. 8.46 & $5,7 \cdot 10^{-4}$ \\
\hline 16 & Steckborn & $\begin{array}{l}4.8 .46 \\
4.8 .46\end{array}$ & $6,3 \cdot 10^{-4}$ \\
\hline 17 & Mammern & 4. 8.46 & $13,3 \cdot 10^{-4}$ \\
\hline 18 & Eschenz & 4. 8.46 & $7,2 \cdot 10^{-4}$ \\
\hline 19 & Stein, Strandbad & 4. 8.46 & $6,8 \cdot 10^{-4}$ \\
\hline 20 & Schaffhausen & 4. 8.46 & $6,6 \cdot 10^{-4}$ \\
\hline
\end{tabular}


weiteres mit denjenigen der Tab. I 3 vergleichen lassen. Trotz des niedergegangenen Regens liegen die Trübungswerte bis auf die Höhe von Haldenstein auffallend tief, und erst die Landquart und die weiter stromabwärts einmündenden Zuflüsse bringen eine wesentliche Erhöhung des Trübungswertes.

In der Zeit vom 30. Juli bis 4. August 1946 wurde eine weitere Trübungsserie aufgenommen im Gebiet des Vorderrheins, des Schweiz-Vorarlberger Rheins, des Boden- und Untersees und im Gebiet des Hochrheins bis Schaff hausen. Die dabei festgestellten Werte sind in Abb. I4 und Tab. I5 wiedergegeben. Auch hier kommt die Trübung des Vorderrheins zum Ausdruck, die durch die Abwassereinleitung bei der Fabrik in Ems noch gesteigert wird. Dann aber klärt sich das Rheinwasser in fortschreitendem Masse bis nach Trübbach. Der hohe Wert von I6,8 im Bodensee bei Romanshorn dürfte auf die Planktonentwicklung des Sees zurückzuführen sein, ebenso der Anstieg der Trübung im Untersee bei Mammern. Mit mittleren Werten, die bei etwa 7 liegen, zieht der Hochrhein weiter bis Schaff hausen.

\section{E. Die Klärung (Sedimentation) der Mineralstoffe getrübter Wässer aus verschiedenen Flußsystemen (Laborversuche)}

Ebenso bedeutungsvoll wie die Trübung selbst ist für ein Wasser die Raschheit seiner Klärung, d. h. die Sedimentation der mineralischen Schwebestoffe. Wir stellten uns deshalb zur Aufgabe, diesen Klärvorgang experimentell festzustellen. $\mathrm{Zu}$ diesem $\mathrm{Zwecke}$ füllten wir von verschiedenen Flußsystemen und Seen Wasser in Glasflaschen ab, schüttelten diese Proben im Laboratorium gehörig durch, bestimmten den Trübungswert und wiederholten die Trübungsmessung in bestimmten Zeitintervallen, die von 5 Sekunden bis über eine Dauer von 5 I Tagen reichten.

Die Bestimmung der Trübungswerte erfolgte an Wasserproben, die jeweils aus der obersten Schicht des Sedimentiergefässes entnommen wurden. Natürlich setzten sich die Schwebeteilchen gemäss ihrer Grösse verschieden rasch ab, so dass sich aus den erzielten Sedimentationszeiten wenigstens grössenordnungsmässig Rückschlüsse auf ihren Äquivalentradius ziehen lassen. Für eine exakte Berechnung der Teilchengrösse der Schwebestoffe reicht die von uns angewandte Methode indes nicht aus. 
Tabelle 16

Sedimentationsperlauf einiger durch anorganische, suspendierte Teilcben getrübter Wässer (Sedimentationsperlauf durch Trübungsmessung perfolgt)

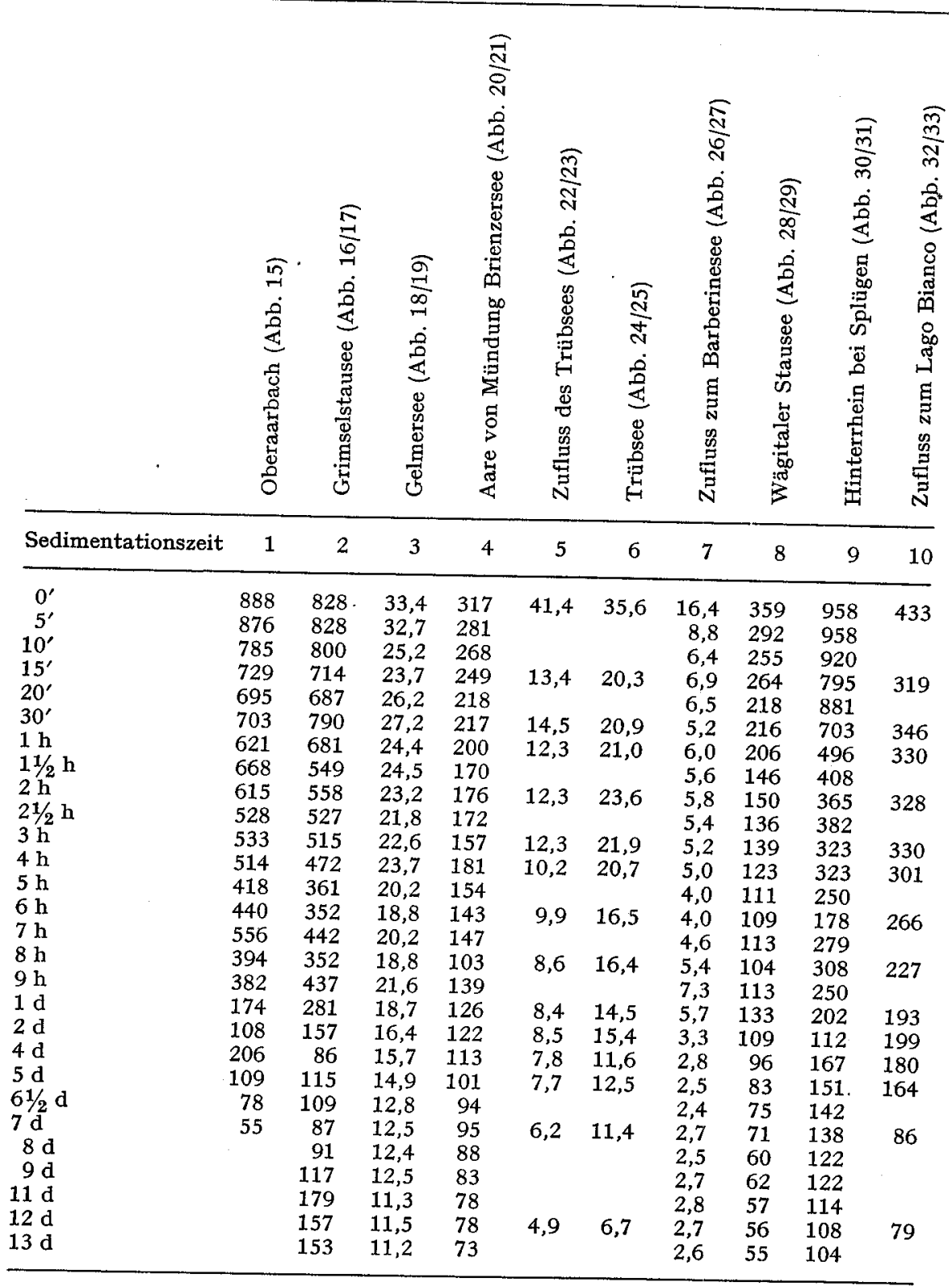


Tabelle 16 (Fortsetzung)

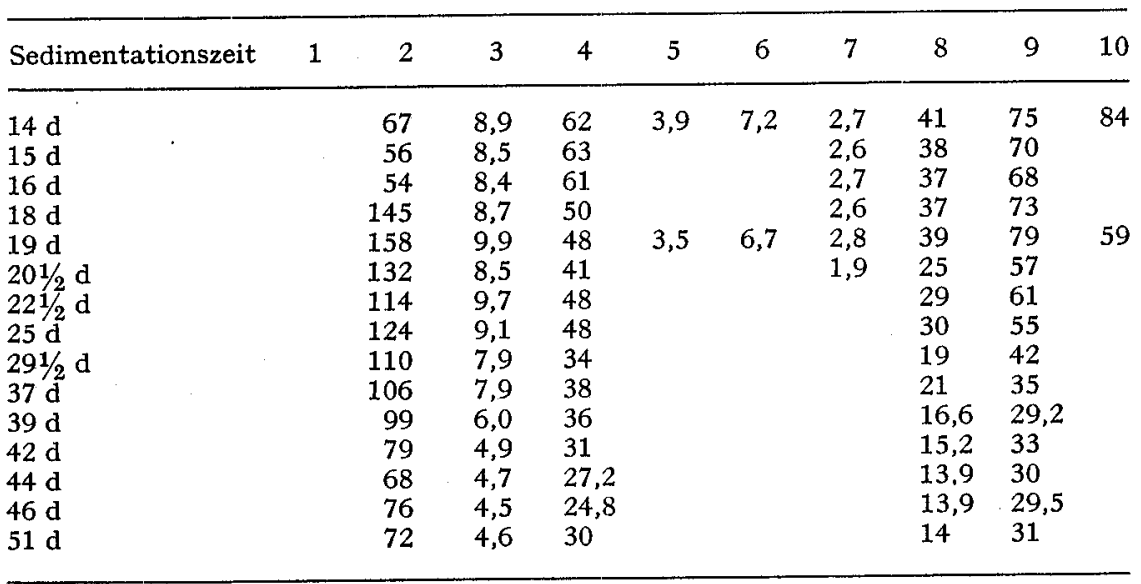

Oberaarbach

Sedimentationsverlauf

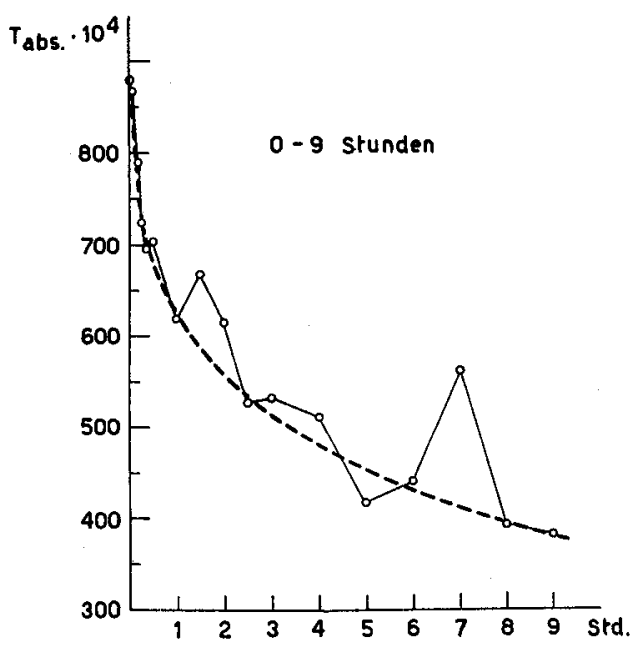

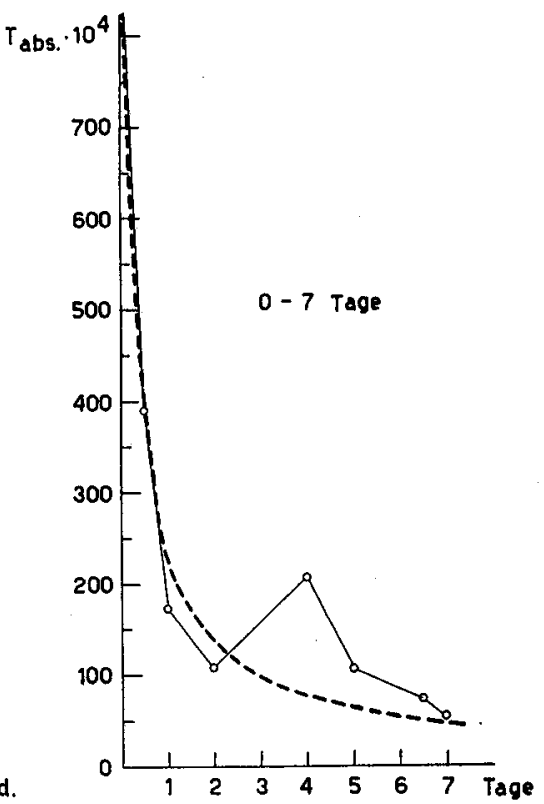

Abbildung 15

Zeitlicher Verlauf des Absetzvorganges in Wasser aus dem Oberaarbach.

Links: erste Phase ( 0 bis 9 Stunden); rechts: Beobachtung während einer Woche. Aufgetragen ist die Trübung als Funktion der Zeit. 


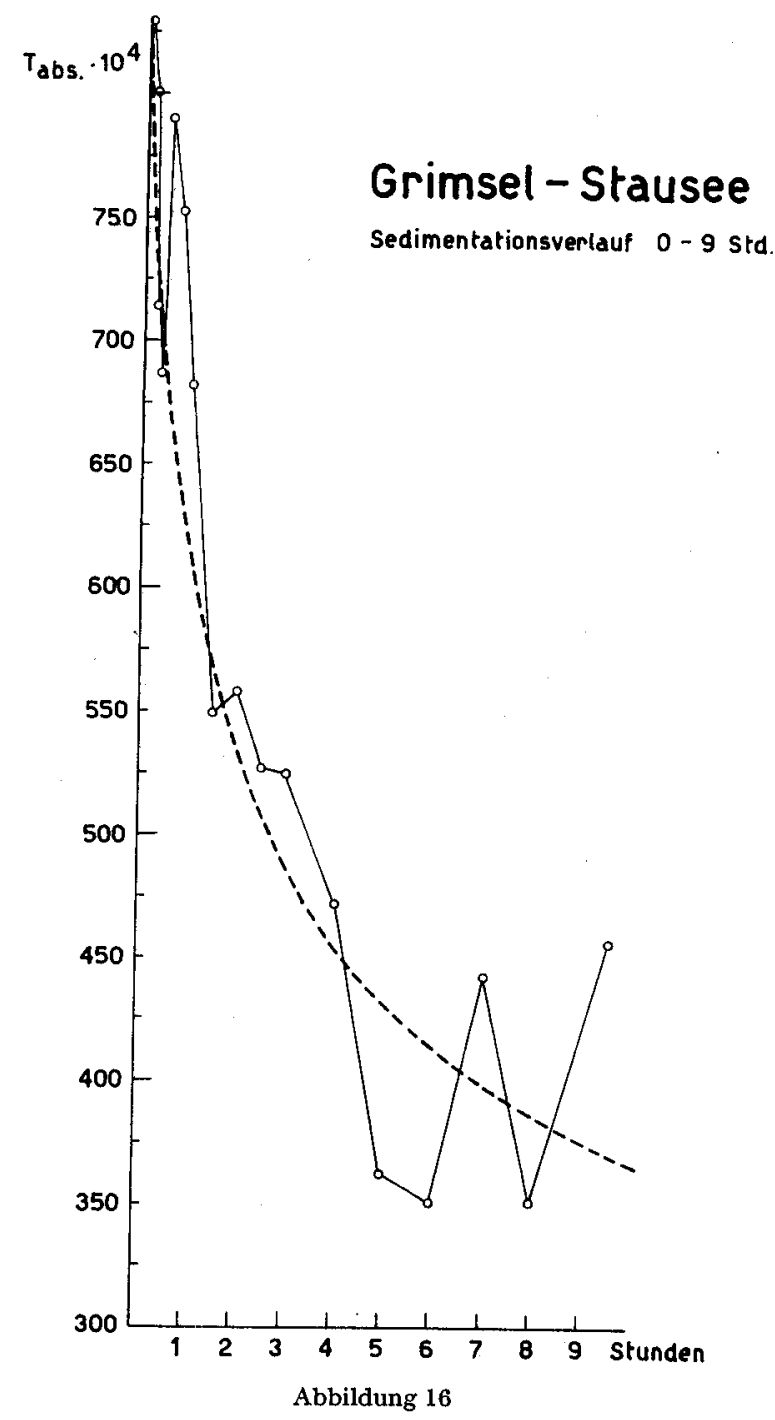

Zeitliche Veränderung der Wassertrübung in Wasser aus dem Grimselstausee. Erste Phase der Beobachtung (9 Stunden).

Mit Rücksicht auf die unterschiedliche Beschaffenheit und Grösse der Schwebestoffe konnte zum vorneherein damit gerechnet werden, dass sich die Klärung der zum Vergleich herangezogenen Wasserproben verschieden rasch vollziehen würde. 
Tabelle 17

Klärungsvorgang in 11 Prohen getrübter Wässer (Abb. 15-33)

\begin{tabular}{|c|c|c|c|c|}
\hline Gewässer & $\begin{array}{l}\text { Anfangs- } \\
\text { trübung } \\
\cdot 10^{-4}\end{array}$ & $\begin{array}{l}\text { Trübung } \\
\text { nach } \\
8 \text { Stunden } \\
\cdot 10^{-4}\end{array}$ & $\begin{array}{l}\text { Trübung } \\
\text { nach } \\
7 \text { Tagen } \\
\cdot 10^{-4}\end{array}$ & $\begin{array}{l}\text { Trübung } \\
\text { nach } \\
18 \text { Tagen } \\
\cdot 10^{-4}\end{array}$ \\
\hline $\begin{array}{l}\text { 1. Oberaarbach } \\
\text { 2. Grimselstausee } \\
\text { 3. Gelmersee } \\
\text { 4. Aare bei Brienz } \\
\text { 5. Zufluss des Trübsees } \\
\text { 6. Trübsee } \\
\text { 7. Zufluss z. Barberinesee } \\
\text { 8. Wägitaler Stausee } \\
\text { 9. Hinterrhein bei Splügen } \\
\text { 10. Zufluss z. Lago Bianco }\end{array}$ & $\begin{array}{l}888 \\
828 \\
33,4 \\
317 \\
41,4 \\
35,6 \\
16,4 \\
359 \\
958 \\
433\end{array}$ & $\begin{array}{l}394 \\
375 \\
19,5 \\
146 \\
8,6 \\
16 \\
4,3 \\
104 \\
255 \\
227\end{array}$ & $\begin{array}{l}55 \\
62 \\
12,5 \\
92 \\
6,2 \\
8,5 \\
2,4 \\
65 \\
110 \\
102\end{array}$ & $\begin{array}{l}\overline{51} \\
9,5 \\
50 \\
3,5 \\
6,2 \\
2,0 \\
35 \\
75 \\
59\end{array}$ \\
\hline
\end{tabular}

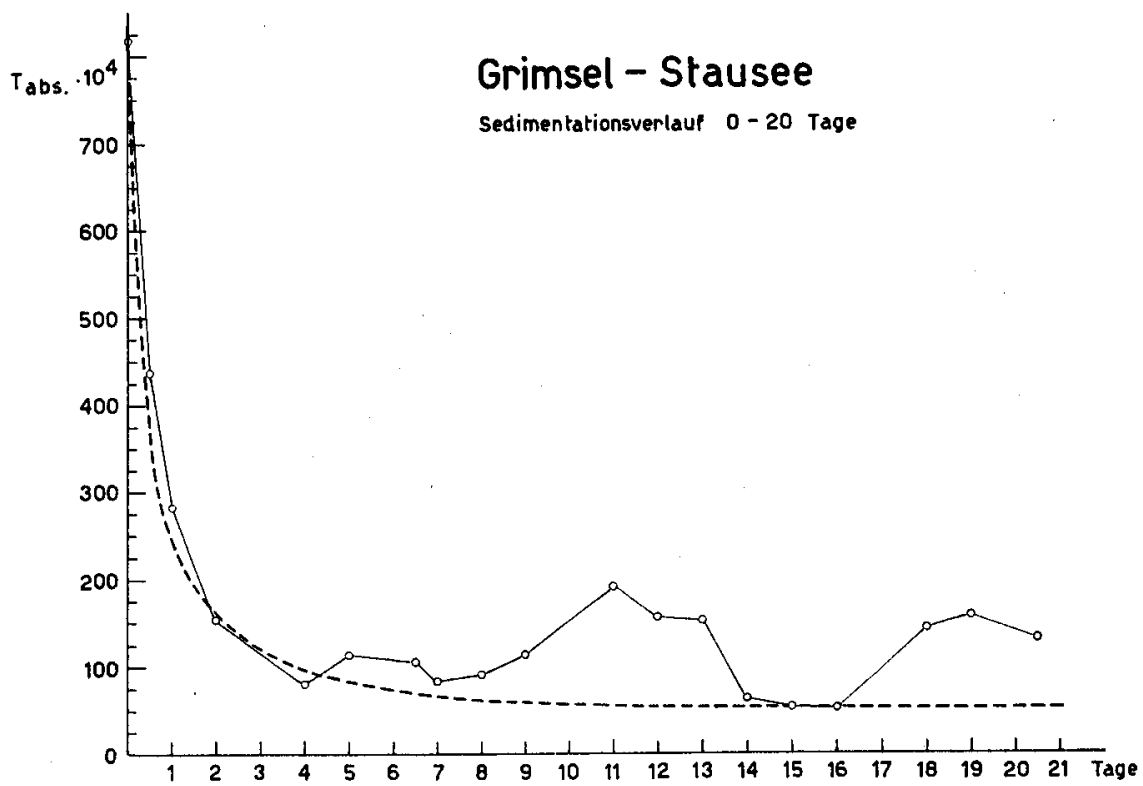

Abbildung 17

Weitere Beobachtung des Absetzvorganges in Wasser aus dem Grimselstausee (erste Phase in $\mathrm{Abb}$. 16 dargestellt). Beobachtungsdauer: 20 Tage. 
Theoretisch vermögen sich in einem mit gutgemischtem, trübem Wasser gefüllten Gefäss in den obersten $5 \mathrm{~cm}$ keine Schwebeteilchen mehr zu halten, deren Durchmesser grösser ist als:

$\begin{array}{lll}\text { nach } 2 \text { Minuten } & 0,02 \mathrm{~mm} & \text { Feinschluff } \\ \text { nach } 4 \text { Stunden } & 0,002 \mathrm{~mm} & \text { Ton } \\ \text { nach 20 Tagen } & 0,0002 \mathrm{~mm} & \text { Kolloidton }\end{array}$

Zwischen 2 Minuten und 4 Stunden Absetzzeit findet sich also nebst noch feineren Teilchen nur noch Feinschluff in Suspension, während

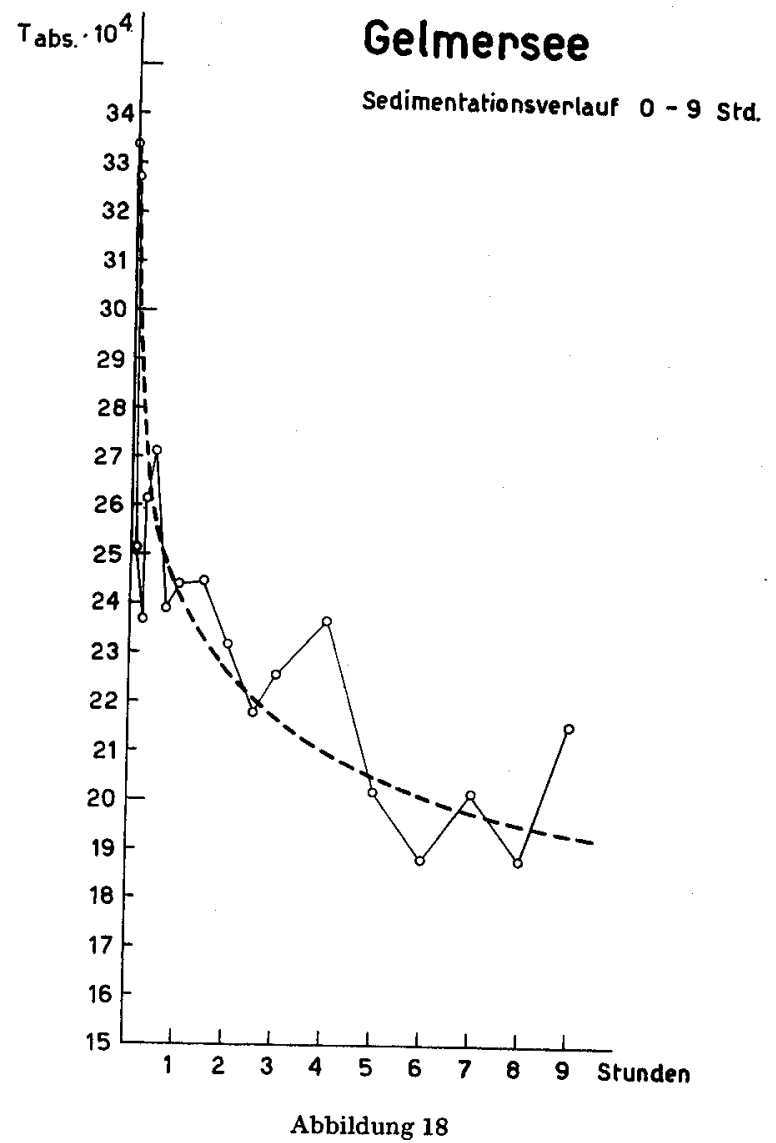

Sedimentationsverlauf in Wasser aus dem Gelmersee. Erste Beobachtungen (9 Stunden). 


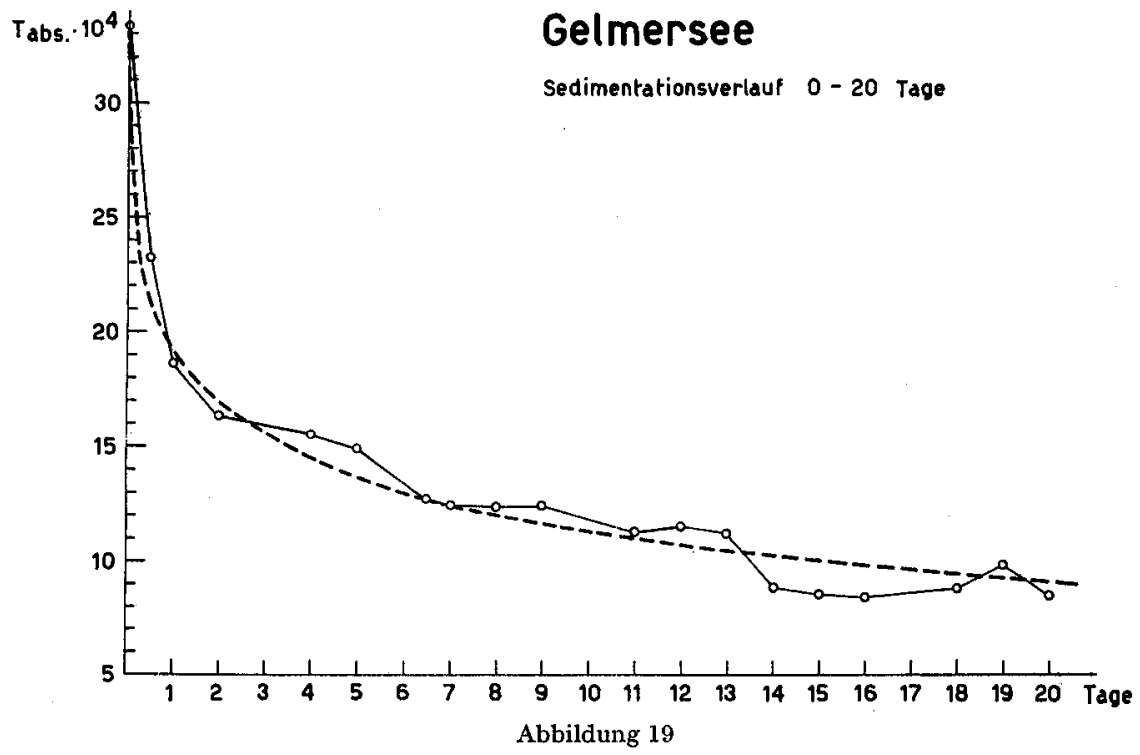

Weitere Beobachtung des Sedimentationsverlaufes in Wasser aus dem Gelmersee (erste Phase in Abb. 18 dargestellt). Beobachtungsdauer: 20 Tage.

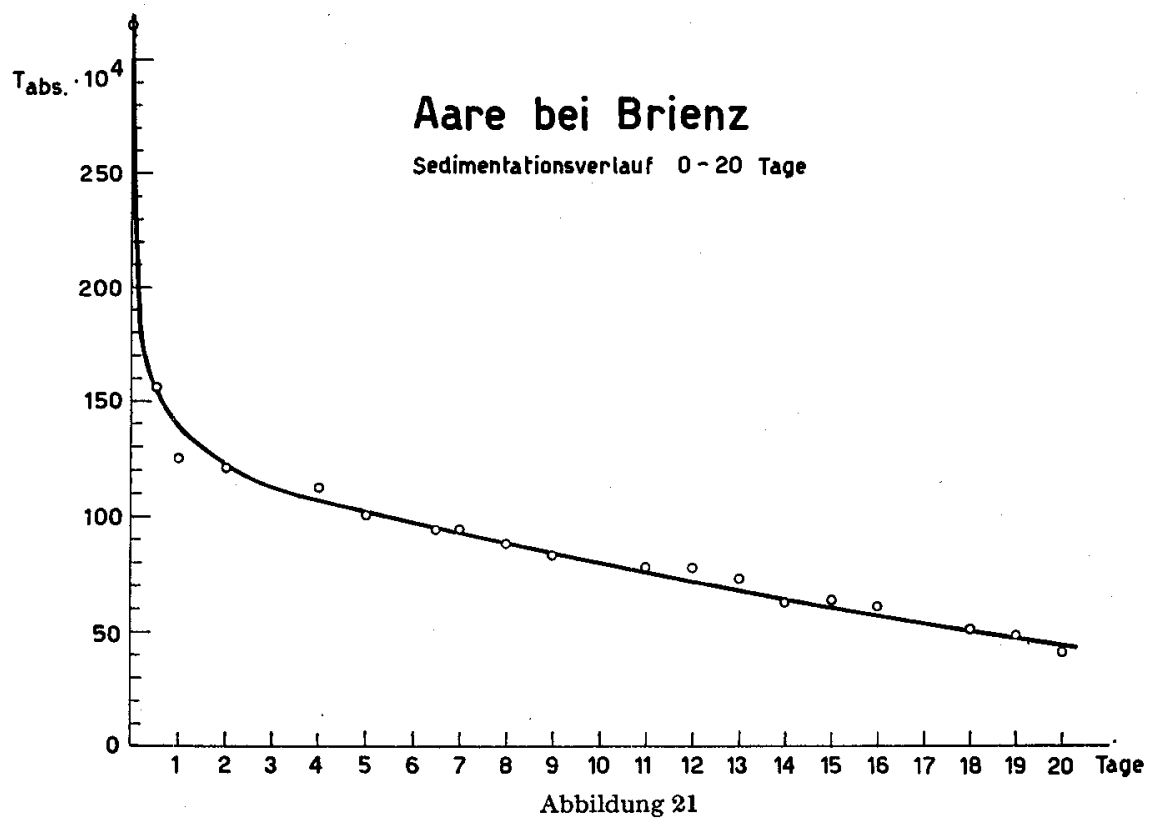

Weitere Beobachtung des Sedimentationsverlaufes im Aarewasser (Aare bei Brienz) bei 20tägiger Beobachtungsdauer (erste Phase in Abb. 20 dargestellt). 
sich in der Zeit von 4 Stunden bis 20 Tagen auch der Ton und erst später auch wenigstens ein Teil des Kolloidtons sedimentiert.

Wie vorauszusehen war, ist der Klärungsvorgang in zeitlicher Hinsicht von Gewässer zu Gewässer verschieden. Je grösser die Schwebeteilchen sind, um so rascher wird sich im allgemeinen ein stehendes Gewässer klären.

Aus den in Tab. I6 zusammengefassten und in Abb. I5-33 graphisch dargestellten Werten ergibt sich der Klärungsverlauf einer Reihe von untersuchten Gewässern.

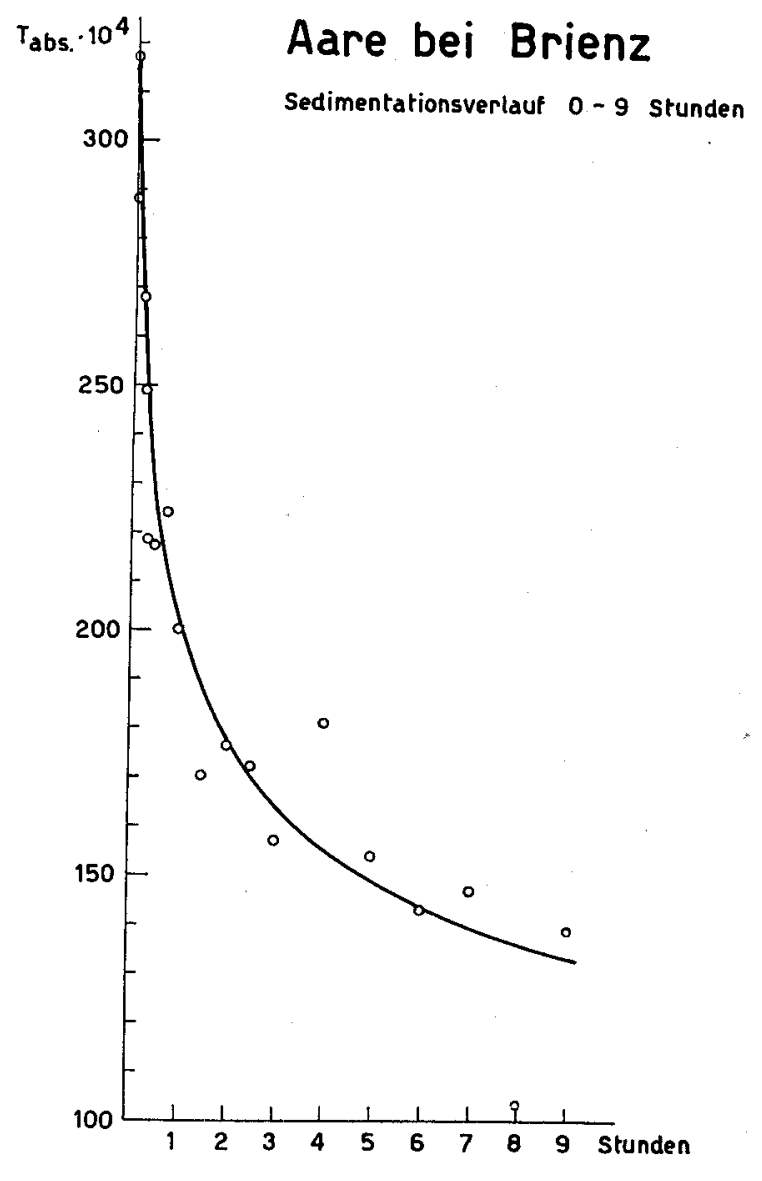

Abbildung 20

Zeitlicher Verlauf der Trübung in Aarewasser (Aare bei Brienz). Erste Phase (9 Stunden). 
Überdies sind in Tab. 17 einige charakteristische Messwerte einander gegenübergestellt, die die Unterschiede im Klärungsverlauf der untersuchten Wässer zur Darstellung bringen.

Im Kurvenverlauf der Abb. 15-33 treten verhältnismässig grosse Fluktuationen der gemessenen Werte in Erscheinung. Dies ist insbesondere bei den Abbildungen $15,16,17,18,24,26,30,32$ und 33 der Fall und dürfte auf die angewendete Untersuchungsmethode zurückzuführen sein. So war es nicht zu vermeiden, dass sich in den Sedimentierungsgläsern Temperaturänderungen einstellten, die im Wasser Konvektionsströmungen auslösten und damit den Sedimentationsvorgang verlangsamten, bzw. etwas störten.

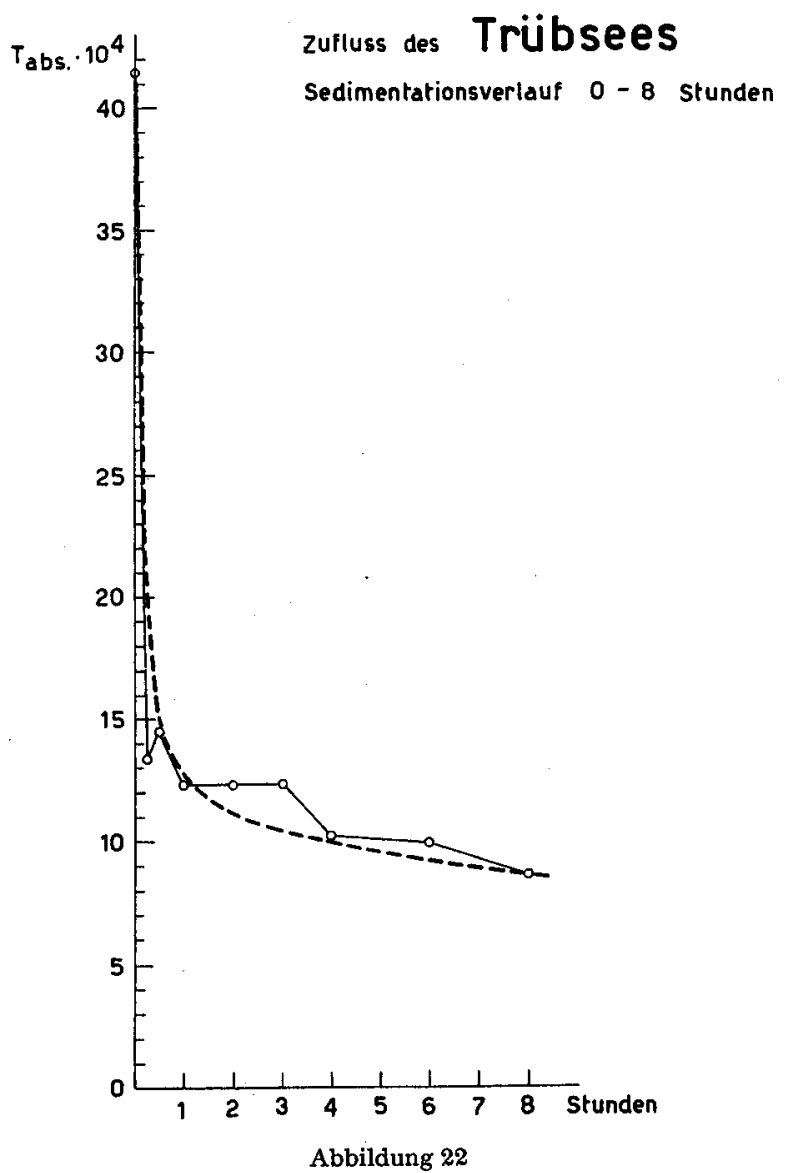

Der Sedimentationsverlauf im Wasser des Trübsees; Beobachtung während der ersten 8 Stunden 


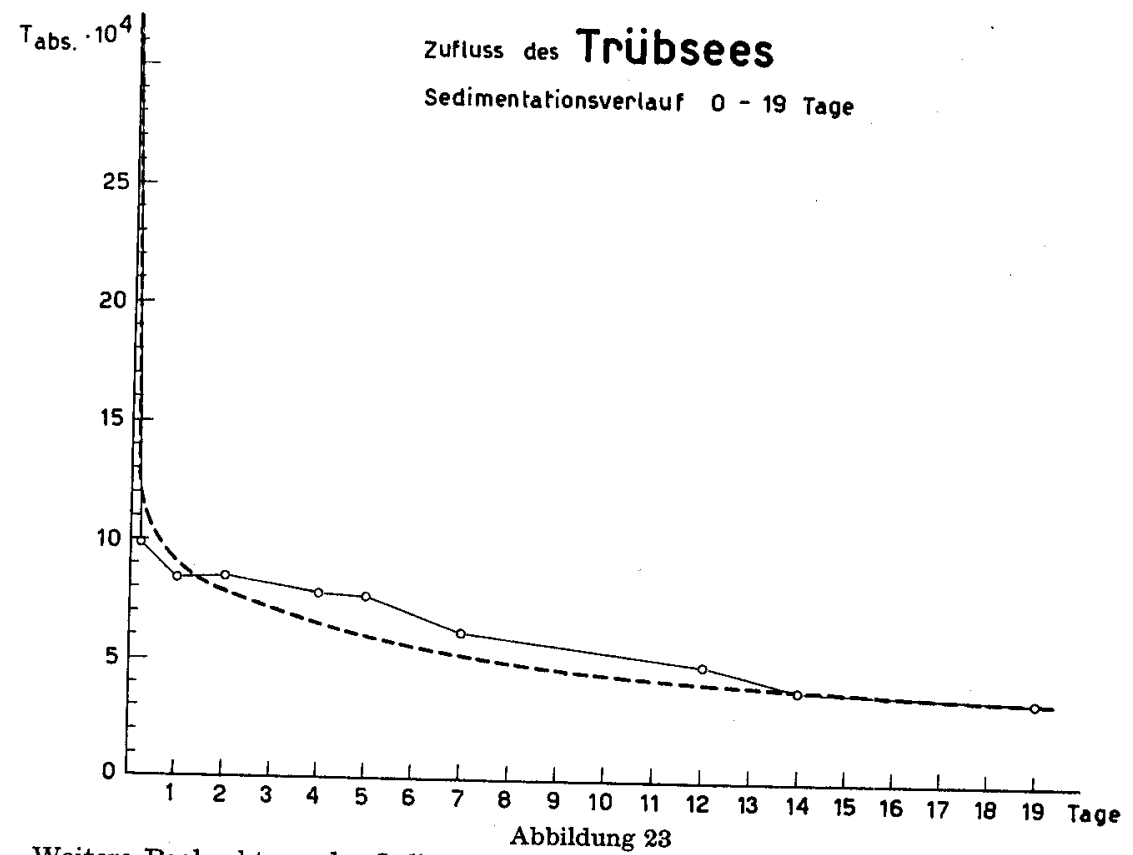

Weitere Beobachtung des Sedimentationsverlaufes im Wasser eines Zuflusses zum Trübsee. Dauer der Beobachtung: 19 Tage. Die erste Phase ist in Abb. 22 dargestellt.

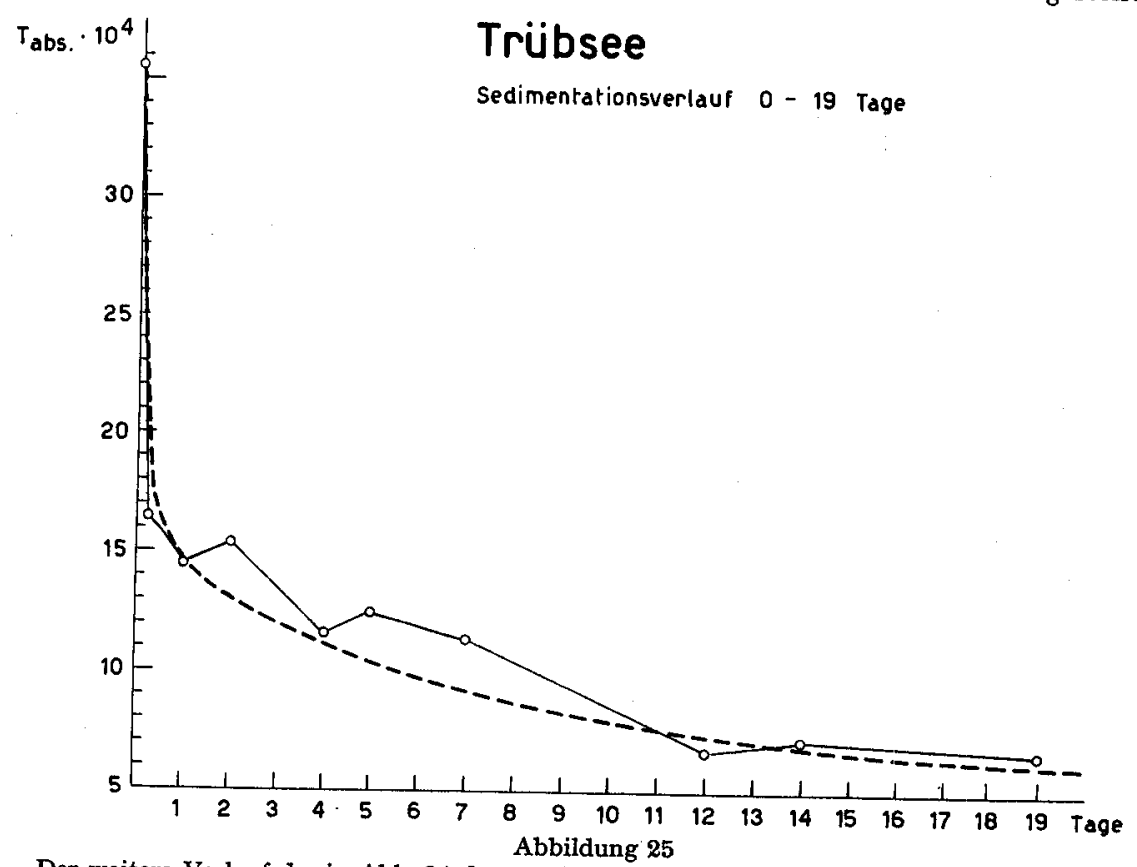

Der weitere Verlauf der in Abb. 24 dargestellten Beobachtungen im Wasser aus dem Trübsee (Dauer der Beobachtungen: 19 Tage). 


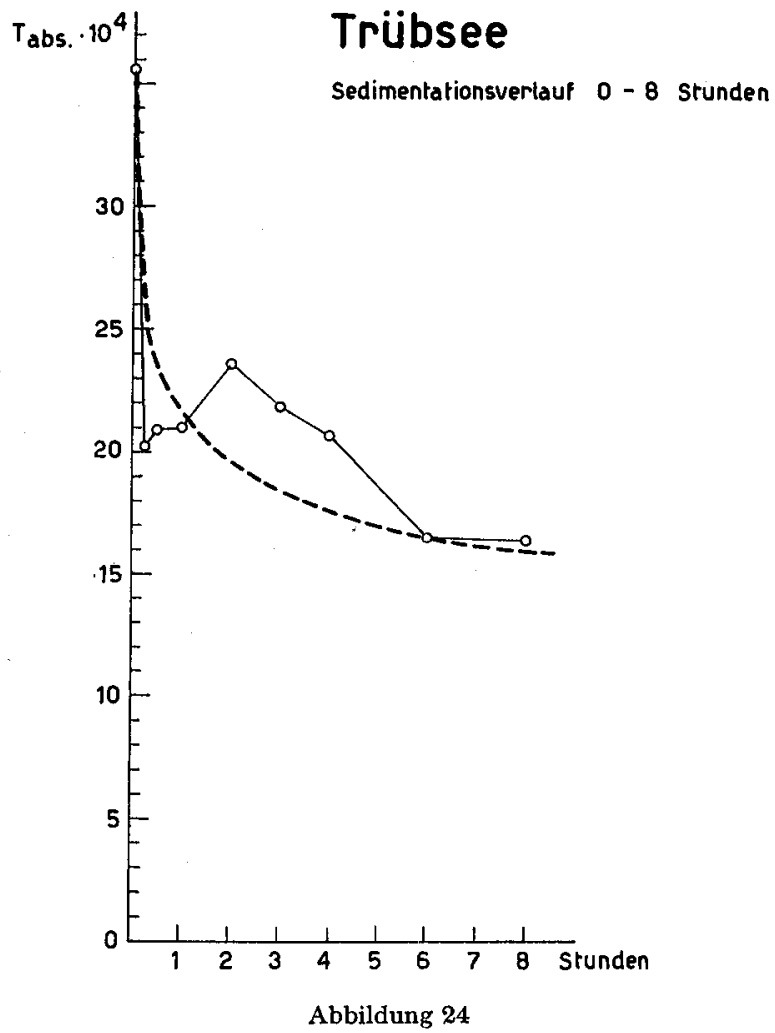

Der Sedimentationsverlauf im Wasser des Trübsees; Beobachtung während der ersten 8 Stunden. 


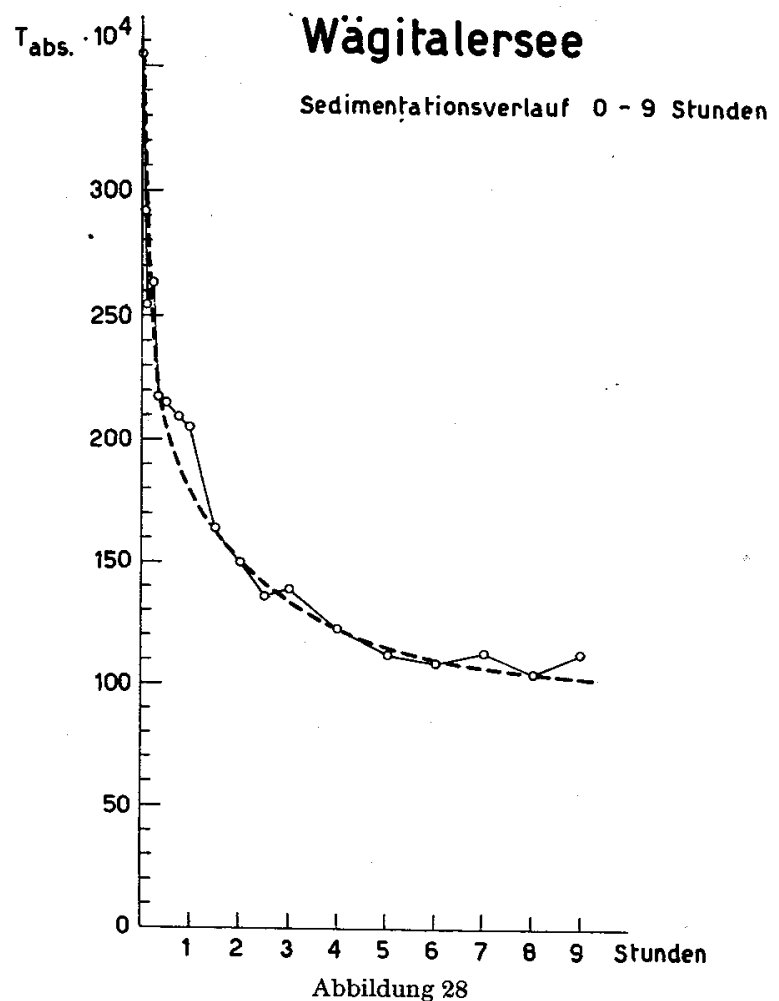

Verlauf der Sedimentation im Wasser des Wägitalersees während 9 Stunden.

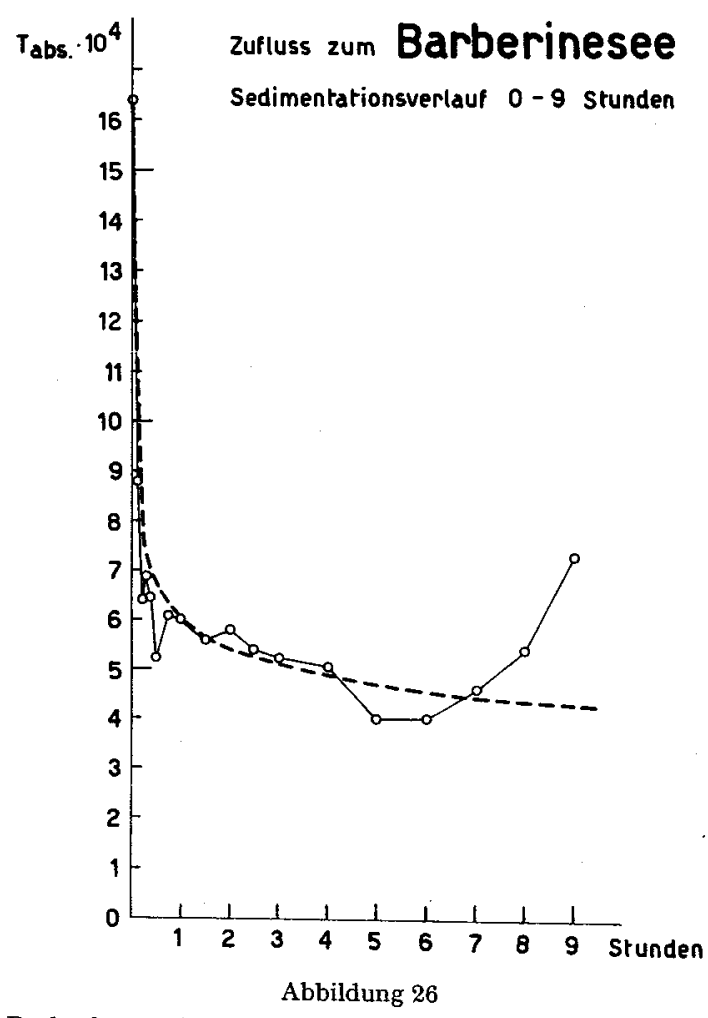

Beobachtung des Sedimentationsverlaufes im Wasser eines Zuflusses zum Lac de Barberine während 9 Stunden. 


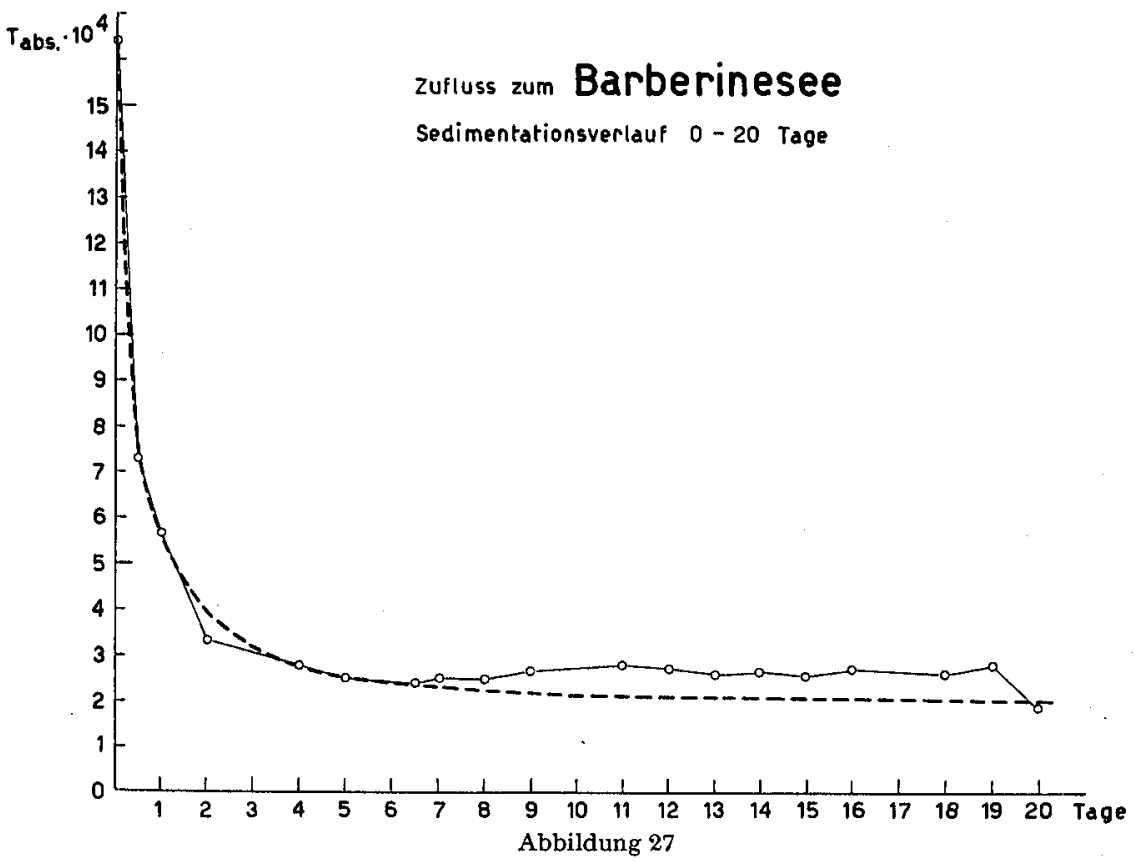

Weitere Beobachtung des Sedimentationsverlaufes im Wasser eines Zuflusses zum Lac de Barberine. Dauer der Beobachtung: 20 Tage. Die erste Phase ist in Abb. 26 dargestellt.

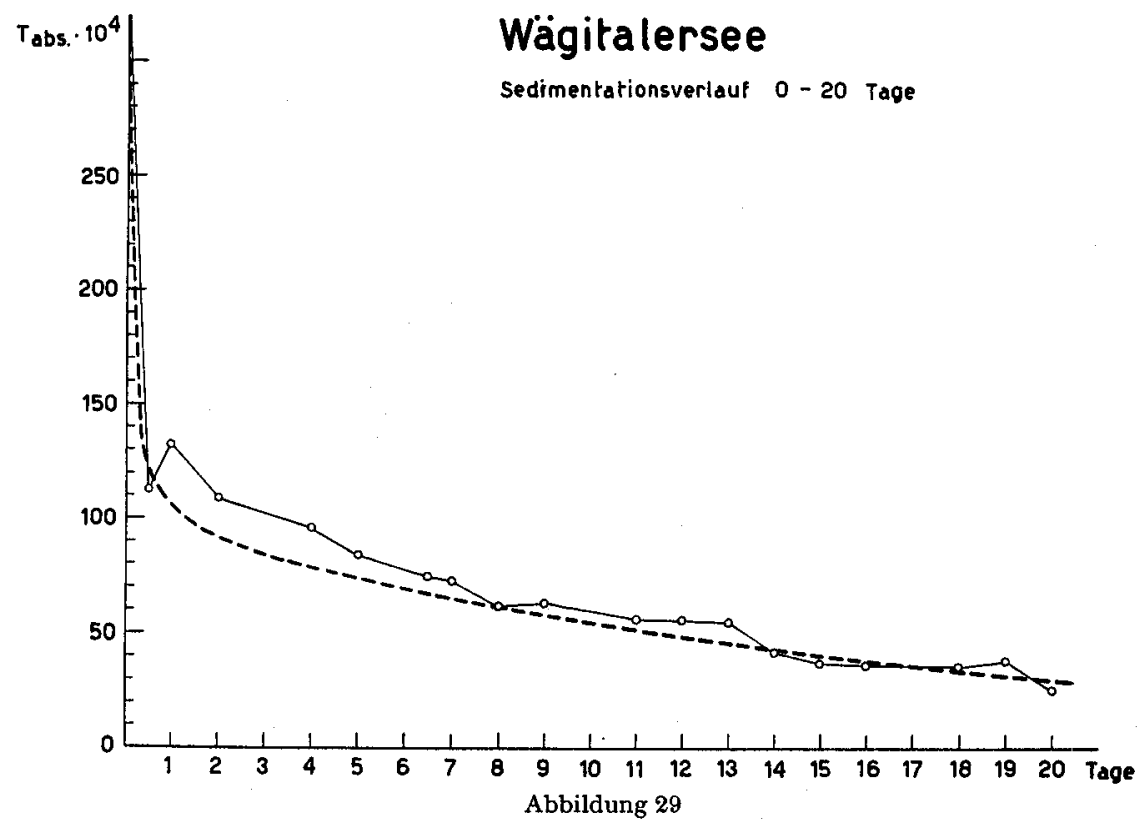

Der weitere Verlauf der in Abb. 28 dargestellten Beobachtungen an Wasser aus dem Wägitalersee (Beobachtungsdauer: 20 Tage; die ersten 9 Stunden sind in Abb. 28 dargestellt). 


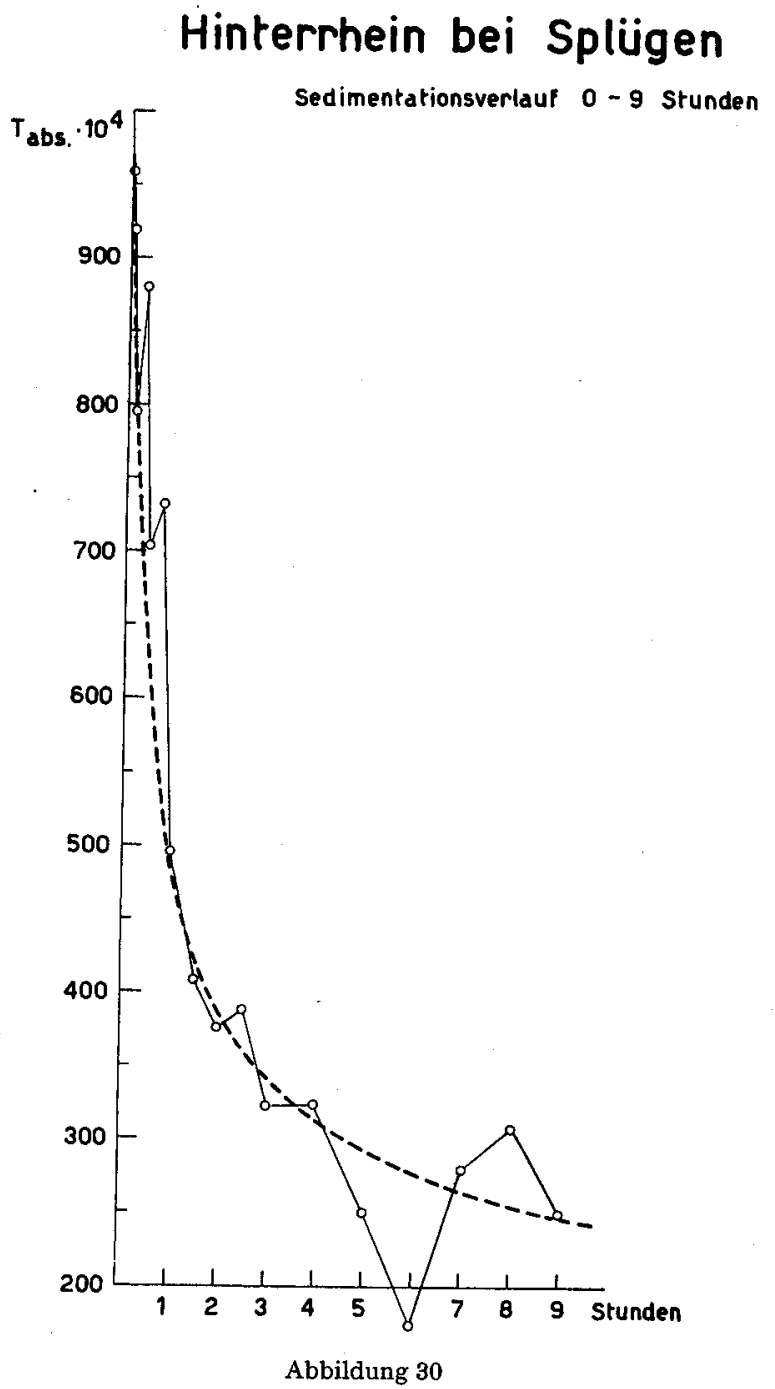

Sedimentationsverlauf in Wasser aus dem Hinterrhein bei Splügen; erste Phase der Beobachtung (9 Stunden). 


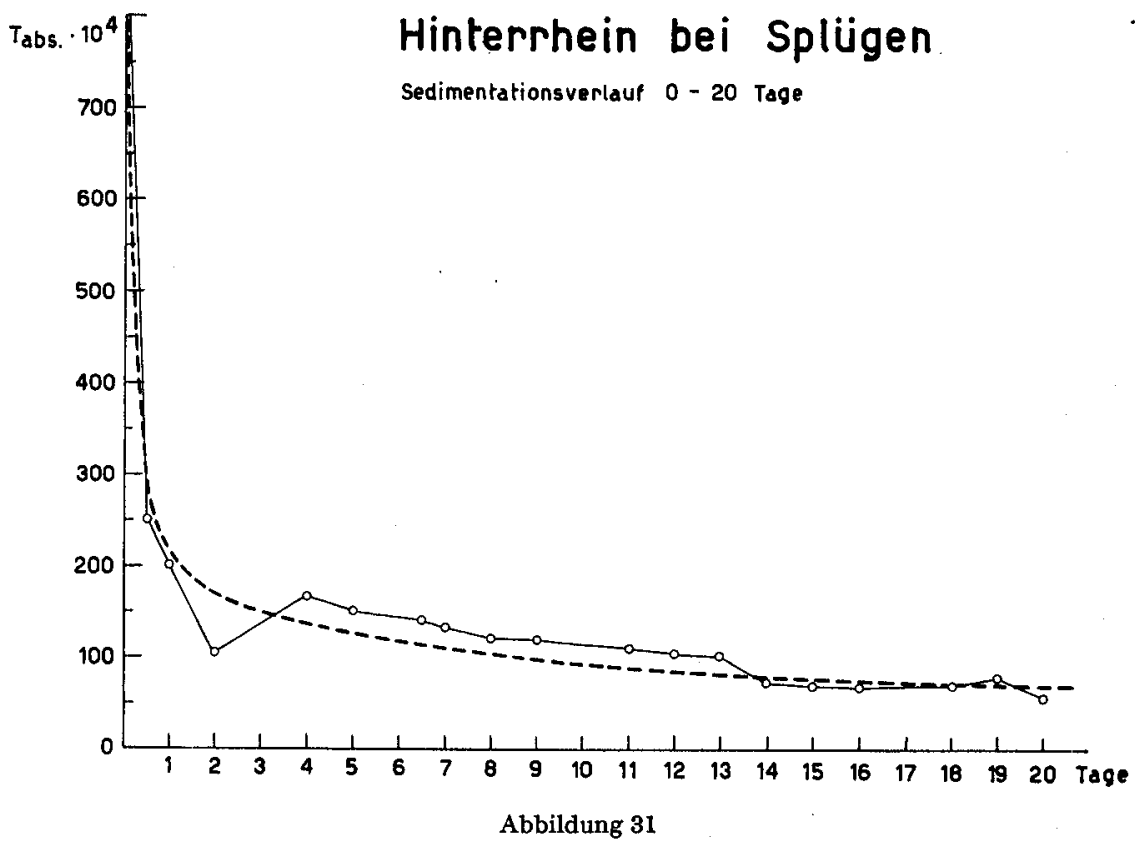

Der weitere Verlauf der Sedimentation im Wasser des Hinterrheins (Splügen) während 20 Tagen; die ersten 9 Stunden sind in Abb. 30 dargestellt.

\section{Zusammenfassung}

Im ersten, der Festlegung der theoretischen Grundlagen der Trübung gewidmeten Kapitel wird die Sinkgeschwindigkeit kleiner Teilchen auf Grund der Gesetze der «Schwebetheorie» von WESENBERG-LUND, W. OSTWALD sowie der Stokesschen Formel diskutiert.

Ein weiteres Kapitel orientiert anhand bisheriger Kenntnisse über die Erscheinungen der Lichtdurchlässigkeit (bzw. -absorption) und des Lichtklimas in verschiedenen Tiefen unserer Seen. Die Trübung der in einer Reihe von Flußsystemen und Seen erhobenen Wässer wurde mittels der absoluten Messung im Pulfrich-Stufenphotometer festgestellt. Sodann wurden die analysierten Proben nach steigenden Trübungswerten geordnet und unterteilt in "Klarseen ", « mitteltrübe» und « trübe» Seen. Schliesslich wurde zusammen mit H. ZüLLIG der Grad der Trübung, der Transparenz und die Seefarbe zueinander in Beziehung gebracht, wobei unterschieden wird zwischen Seen, die a) durch vorwiegend anorganische Stoffe, b) durch 


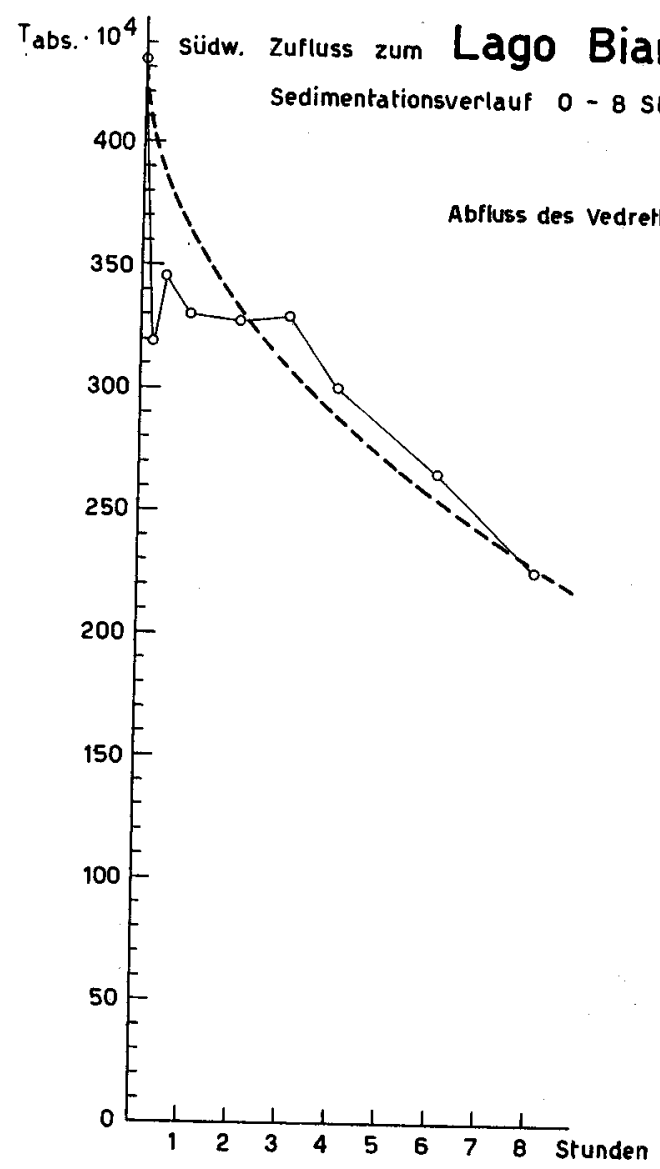

Abbildung 32

Sedimentationsverlauf im Abfluss des Vedretta di Gambrena (südwestlicher Zufluss zum Lago Bianco) während der ersten 8 Stunden).

vorwiegend Oscillatoria-armes Plankton, c) durch vorwiegend Oscillatoria rubescens getrübt sind.

Die in mehreren Tabellen und Abbildungen wiedergegebenen Werte der Wassertrübung spiegeln die unterschiedlichen Verhältnisse wider, die sich im Laufe einer ausgedehnteren Flußstrecke oder in einem See ergeben aus der Mischung des verschieden stark mit Schwebestoffen belasteten Wassers von Haupt- und Nebenfluss, sodann aus der fortschreitenden oder von Strecke zu Strecke wechselnden Sedimentation, und natürlich auch von der lokalen oder regionalen Wetterlage (Niederschläge und Schneeschmelze). 
In ausgedehnten und zum Teil über Monate hinweg durchgeführten Sedimentationsversuchen im Laboratorium wurde schliesslich der Klärvorgang von Wässern verschiedener Herkunft in Funktion der Zeit untersucht. Dabei ergaben sich unterschiedliche Kurven, die ein Bild zu vermitteln vermögen über den mittleren Durchmesser der die Trübung verursachenden sedimentierbaren, anorganischen Partikeln.

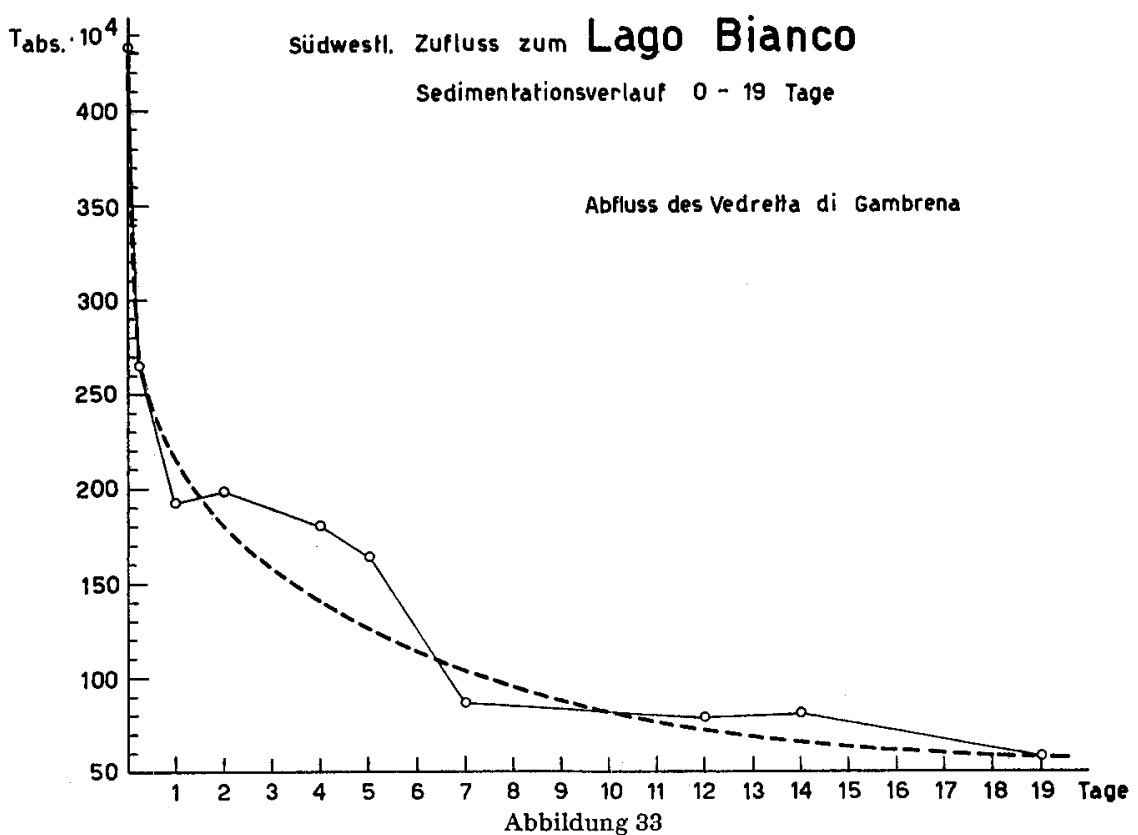

Der weitere Verlauf der Sedimentation im Abfluss des Vedretta di Gambrena; Beobachtungen während 19 Tagen.

\section{LITERATUR VERZEICHNIS}

FOREL, F.-A., Le Léman I-III (Lausanne I 892-1904).

FOREL, F.-A., Handbuch der Seenkunde (Stuttgart I90I).

Hutchinson, G. E., Treatise on Limnology I (New York 1957).

JAAG, O., Corrélation entre la turbidité, la transparence et la couleur de quelques-unes de nos eaux de surface, Bulletin de la Société vaud. des sci. nat. 68, 205-212 (1963).

RUTTNER, F., Grundriss der Limnologie (Berlin 1962).

SAUberer, F., Zur Metbode der Durcbsicbtigkeitsmessung im Wasser und deren Anwendung in der Limnologie, Arch. f. Hydrobiol. 33 (I938).

Westrhal, W., Pbysik, S. I77 (Berlin 1959).

Separatdruck aus der Schweiz. Z. Hydrologie 26, Fasc. I, I964.

Herausgegeben mit Unterstützung der Stiftung der Wirtsch aft zur Förderung des Gewässerschutzes in der Schweiz. 